\title{
Trypsin activity governs increased susceptibility to pancreatitis in mice expressing human PRSS1 ${ }^{\mathrm{R} 122 \mathrm{H}}$
}

\author{
Fu Gui, ${ }^{1}$ Yuebo Zhang, ${ }^{1}$ Jianhua Wan, ${ }^{1}$ Xianbao Zhan, ${ }^{1}$ Yao Yao, ${ }^{1}$ Yinghua Li, ${ }^{1}$ Ashley N. Haddock, ${ }^{1}$ Ji Shi, ${ }^{1}$ Jia Guo, ${ }^{1}$ Jiaxiang Chen, \\ Xiaohui Zhu, ${ }^{1}$ Brandy H. Edenfield, ${ }^{1}$ Lu Zhuang, ${ }^{1}$ Cheng Hu, ${ }^{2}$ Ying Wang, ${ }^{3}$ Debabrata Mukhopadhyay, ${ }^{3}$ Evette S. Radisky, ${ }^{1}$ \\ Lizhi Zhang, ${ }^{4}$ Aurelia Lugea, ${ }^{2}$ Stephen J. Pandol, ${ }^{2}$ Yan $\mathrm{Bi}^{5}{ }^{5}$ and Baoan $\mathrm{Ji}^{1}$ \\ 'Department of Cancer Biology, Mayo Clinic, Jacksonville, Florida, USA. ²Department of Medicine, Cedars-Sinai Medical Center, Los Angeles, California, USA. ${ }^{3}$ Department of Biochemistry and Molecular \\ Biology, ${ }^{4}$ Division of Anatomic Pathology, and ${ }^{5}$ Division of Gastroenterology and Hepatology, Mayo Clinic, Jacksonville, Florida, USA.
}

\begin{abstract}
Currently, an effective targeted therapy for pancreatitis is lacking. Hereditary pancreatitis (HP) is a heritable, autosomaldominant disorder with recurrent acute pancreatitis (AP) progressing to chronic pancreatitis (CP) and a markedly increased risk of pancreatic cancer. In 1996, mutations in PRSS1 were linked to the development of HP. Here, we developed a mouse model by inserting a full-length human $P R S S 1^{R 122 H}$ gene, the most commonly mutated gene in human HP, into mice. Expression of PRSS1 ${ }^{\mathrm{R} 122 \mathrm{H}}$ protein in the pancreas markedly increased stress signaling pathways and exacerbated AP. After the attack of AP, all PRSS1 ${ }^{\mathrm{R} 122 \mathrm{H}}$ mice had disease progression to $\mathrm{CP}$, with similar histologic features as those observed in human HP. By comparing PRSS1 ${ }^{122 \mathrm{H}}$ mice with PRSS1 ${ }^{\mathrm{WT}}$ mice, as well as enzymatically inactivated Dead-PRSS1 ${ }^{\mathrm{R} 122 \mathrm{H}}$ mice, we unraveled that increased trypsin activity is the mechanism for $\mathrm{R} 122 \mathrm{H}$ mutation to sensitize mice to the development of pancreatitis. We further discovered that trypsin inhibition, in combination with anticoagulation therapy, synergistically prevented progression to $\mathrm{CP}$ in PRSS1 ${ }^{\mathrm{R} 122 \mathrm{H}}$ mice. These animal models help us better understand the complex nature of this disease and provide powerful tools for developing and testing novel therapeutics for human pancreatitis.
\end{abstract}

\section{Introduction}

Pancreatitis, both acute and chronic, results in significant morbidity and mortality (1-3). With approximately 275,000 hospitalizations/year in the United States (4), acute pancreatitis (AP) is the most common gastrointestinal diagnosis and costs an estimated $\$ 2.6$ billion per year due to inpatient costs alone (5). The mortality of AP is $3 \%-6 \%$, whereas in severe cases the rate increases to $30 \%$ (6). AP also ranks as the fifth leading cause of in-hospital deaths (6). Recurrent AP (RAP) can progress to chronic pancreatitis $(\mathrm{CP})$, which causes pain, maldigestion, diabetes mellitus, and increased risk for developing pancreatic cancer $(7,8)$. Currently there are no effective preventive or therapeutic strategies for this disease, primarily due to the lack of an ideal animal model mimicking the human form of the disease and our deficient understanding of its pathogenesis (9).

More than a century ago, Chiari (10) proposed that pancreatitis was an autodigestive disease. During the past 3 decades, researchers have revealed that premature activation of trypsinogen occurs in the pancreas of both human pancreatitis and experimental pancreatitis (11-15). Because trypsin is capable of degrading proteins and initiating other zymogen activation cascades, premature activation of trypsinogen in pancreatic acinar cells has been consid-

Authorship note: FG, YZ, and JW are co-first authors. YB and BJ share senior authorship. Conflict of interest: The authors have declared that no conflict of interest exists. Copyright: ( 2020 , American Society for Clinical Investigation.

Submitted: May 9, 2019; Accepted: September 18, 2019; Published: November 18, 2019. Reference information: / Clin Invest. 2020;130(1):189-202.

https://doi.org/10.1172/JCl130172. ered a key initiator of this disease. This notion is strongly supported by the observation that gain-of-function trypsinogen PRSS1 $\mathrm{R} 122 \mathrm{H}$ mutations and loss-of-function mutations of the potent pancreatic serine protease inhibitor Kazal type 1 (SPINK1) have been associated with human hereditary pancreatitis (HP) (16-21). $\mathrm{HP}$ is a heritable, autosomal dominant, pancreatic inflammatory disorder with greater than $80 \%$ penetrance. Clinically, HP is characterized by RAP that has an unusually early onset (age 5-23 years) and eventually develops into CP. Of note, the cumulative risk of pancreatic cancer in patients with HP is $44 \%$ by age 70 years $(7,8)$.

Because the biochemical characteristics of mouse and human PRSS1 are different, an animal model expressing human $\mathrm{PRSS}^{\mathrm{R} 122 \mathrm{H}}$ shall be a prototype for studying the pathogenesis and testing therapies of pancreatitis. Unfortunately, since the discovery of the $P R S S 1^{\mathrm{R} 122 \mathrm{H}}$ mutation in HP in $1996(20,22,23)$, mouse models of this disease have been notoriously difficult to generate $(24,25)$. In this study, we aim to develop a human relevant animal model of AP and CP by expressing human PRSS1 ${ }^{\mathrm{R} 122 \mathrm{H}}$, elucidate its fundamental mechanisms, and discover novel effective therapies.

\section{Results}

A BAC transgene conferred high levels of human PRSS1 ${ }^{R 122 H}$ expression. Based on our experience with genetically engineered mouse models and recent advancements in understanding of the biochemical characteristics of mouse and human PRSS1 pioneered by Sahin-Toth (26-28), we reasoned that both the species and expression level of the PRSS1 gene were critical for successfully modeling the disease in mice. Therefore, we decided to use a human bacterial artificial chromosome (BAC) harboring the full-length 
A

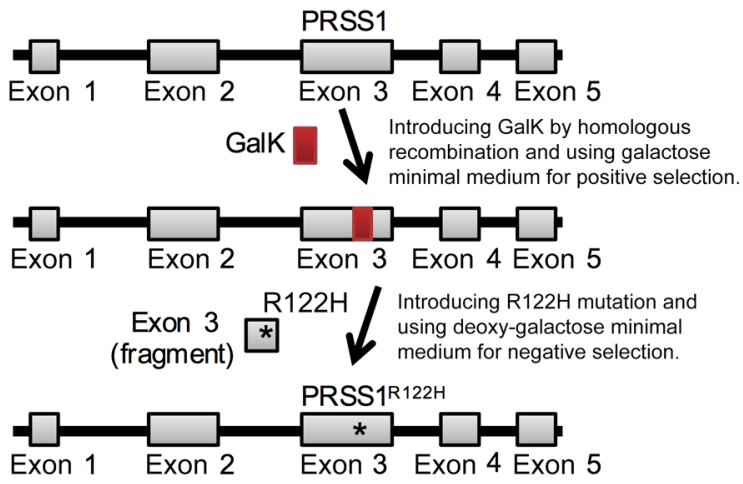

B
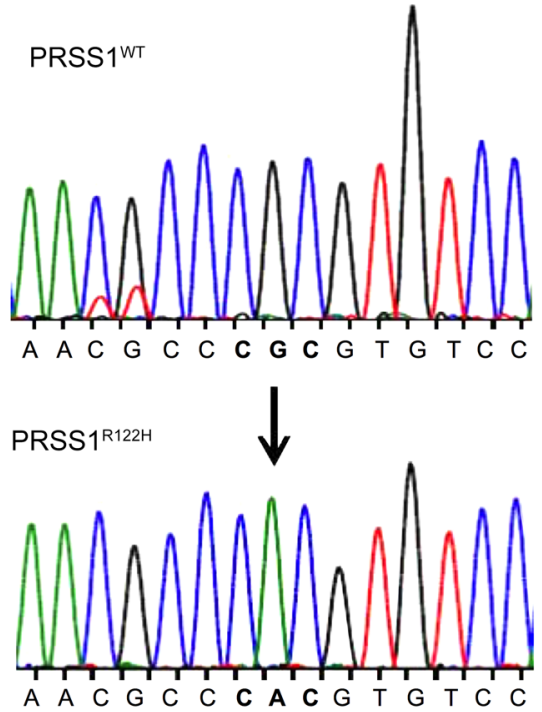

C

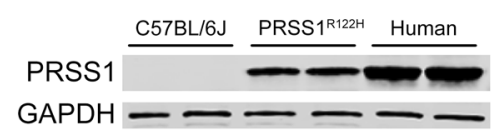

D

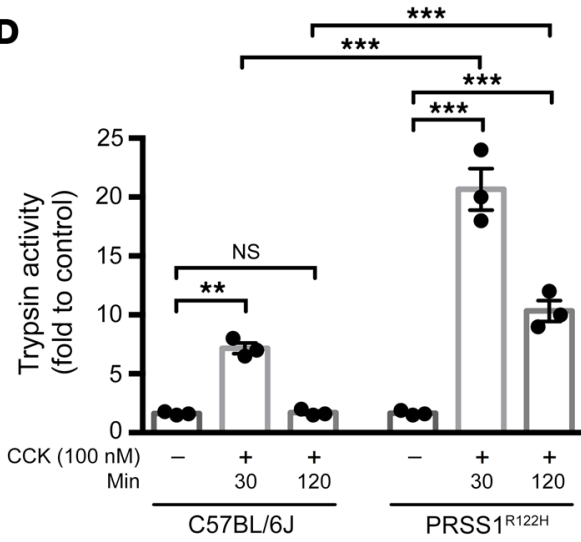

human PRSS1 gene for faithful recapitulation of its expression (Figure 1A). This BAC contains full-length human PRSS1 gene promoter, exons, introns, and 3 '-untranslated region (UTR) to ensure native gene expression regulation. An R122H point mutation was introduced using GalK-mediated recombineering (PRSS1 $\left.{ }^{\mathrm{R} 122 \mathrm{H}}\right)$ (Figure 1A and ref. 29). The correct mutation targeting was verified by Sanger DNA sequencing (Figure 1B). PRSS1 ${ }^{\mathrm{R} 122 \mathrm{H}}$ was highly expressed in the pancreas of transgenic mice made with this construct (Figure 1C). Spontaneous pancreatitis was not observed (Supplemental Figure 1; supplemental material available online with this article; https://doi.org/10.1172/JCI130172DS1); likely other stimuli are required to initiate the development of the disease. Similarly, in humans, carriers of PRSS1 ${ }^{\mathrm{R} 122 \mathrm{H}}$ are not born with pancreatitis. Instead, their first episode of AP attack occurs at a median age of 10 years (30). However, upon stimulation of cholecystokinin (CCK) receptors, increased and prolonged trypsin activity was observed in the pancreatic acini prepared from these transgenic mice (Figure 1D and ref. 31). This observation supports the previously established theory that the $\mathrm{R} 122 \mathrm{H}$ mutation would disrupt an important fail-safe defensive mechanism against activated trypsin $(20,32)$ and the expression of mutant PRSS1 may sensitize the mice to the development of pancreatitis.

Transgenic expression of human PRSS1 R122H led to severe AP. Cerulein, an analog of CCK, is commonly used for inducing pancreatitis in rodents (33). Because increased and prolonged trypsin activity was observed upon CCK receptor stimulation in the PRSS1 ${ }^{\mathrm{R} 122 \mathrm{H}}$ mice, we predicted that more severe pancreatitis would develop in these mice. Indeed, upon stimulation with cerulein (Figure 2A), pancreata from these mice displayed severe macroscopic edema as compared with those from WT C57BL/6 J mice (Figure 2B). The pancreatic edema was further confirmed by increased pancreas-to-body weight ratio (Figure 2C). Elevated serum amylase, a hallmark of pancreatic acinar cell damage during pancreatitis, further suggested that more severe pancreatitis developed in the PRSS1 ${ }^{\mathrm{R} 122 \mathrm{H}}$ mice (Figure 2D). Histologically, the pancreata from PRSS1 ${ }^{\mathrm{R} 122 \mathrm{H}}$ mice showed increased interstitial space, an indication of edema, pancreatic acinar cell damage and massive inflammatory cells infiltration (Figure 2E), lung inflammation (Supplemental Figure 2), and histology score of pancreatitis (Figure 2F). Immunohistochemical analysis revealed that $\mathrm{CD} 11 \mathrm{~b}$-positive leukocytes included macrophages (F4/80) and neutrophils (Gr-1) (Figure 2G and Supplemental Figure 3). The activation of the proinflammatory NF-KB signaling pathway, a master regulator of inflammation (34), was measured by detecting p65 nuclear translocation (Figure 2, H and I). The upregulation of NF- $\mathrm{KB}$ downstream cytokine expression provides an explanation for the severe pancreatic inflammation observed in the PRSS1 ${ }^{\mathrm{R} 122 \mathrm{H}}$ mice (Figure 2J). The increased severity of AP in PRSS1 ${ }^{\mathrm{R} 122 \mathrm{H}}$ mice was further confirmed in L-arginine-induced pancreatitis model (Supplemental Figure 4). 
A

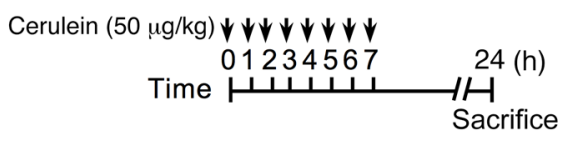

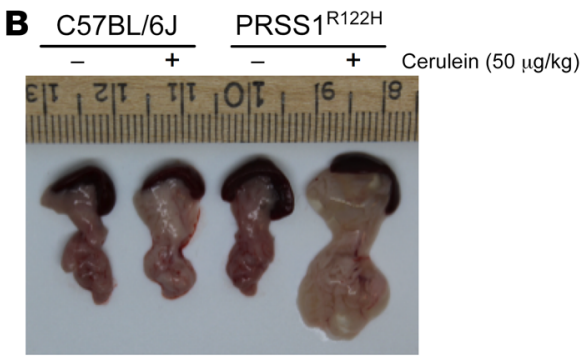

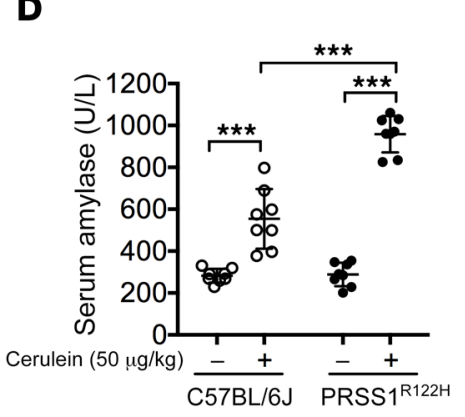

E

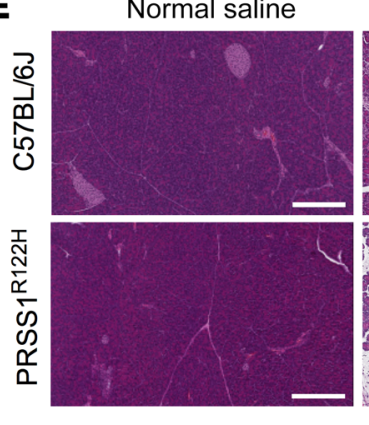

C

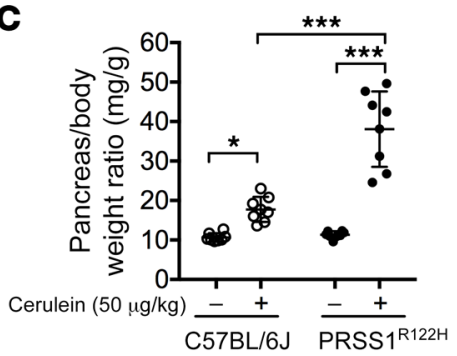

G

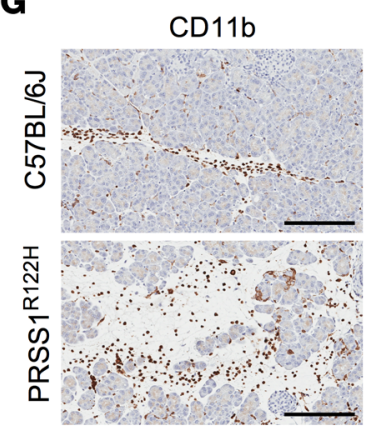

$\mathrm{F} 4 / 80$

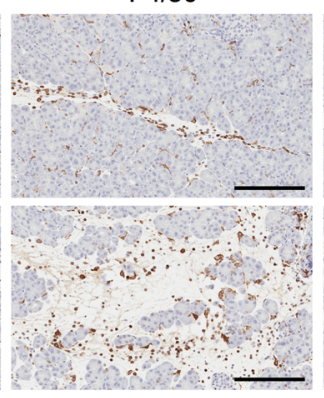

Gr-1

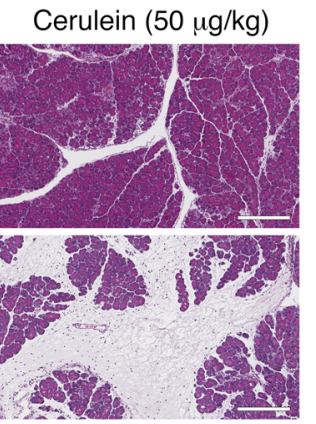

$\mathbf{F}$

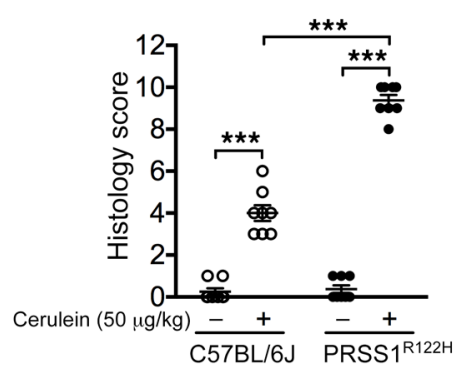

I

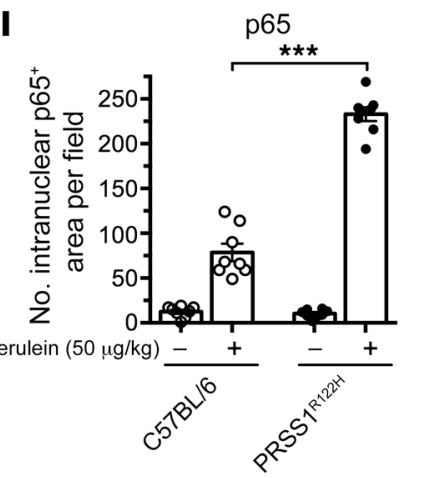

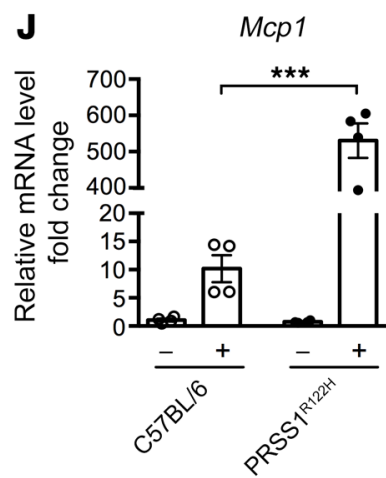
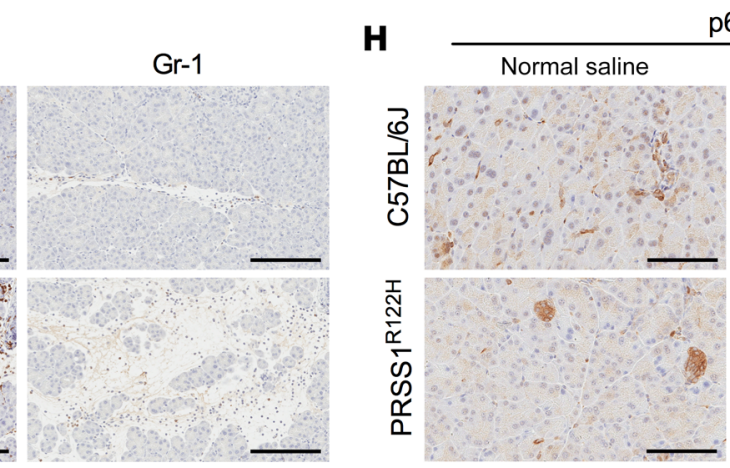

p65

Cerulein $(50 \mu \mathrm{g} / \mathrm{kg})$

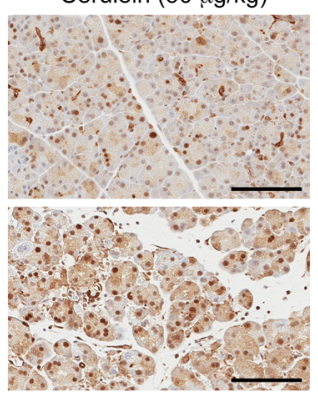

$\| 1 b$
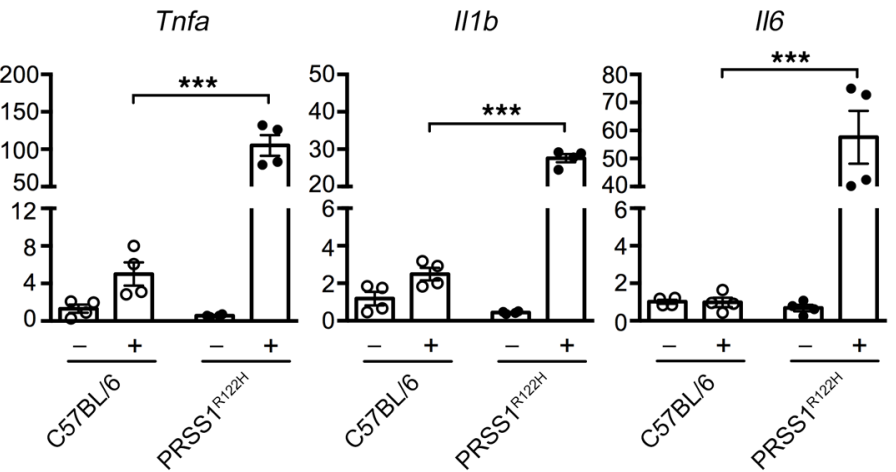

Figure 2. Transgenic expression of human PRSS1R122H caused severe AP. (A) Schema of cerulein-induced AP protocol. (B) Representative photos of pancreata from transgenic human PRSS1 ${ }^{\mathrm{R} 22 \mathrm{H}}$ mice and C57BL/6) mice 24 hours after cerulein induction $(n=8)$. (C) Significant increase in pancreatic edema (pancreas-to-body weight ratio) in PRSS1 ${ }^{1122 \mathrm{H}}$ mice 24 hours after cerulein induction. Mean $\pm \operatorname{SEM}(n=8) .{ }^{*} P<0.05$; ${ }^{* * *} P<0.001 ; 2$-way ANOVA with Tukey's test. (D) Serum amylase levels after 24 hours of cerulein induction. Mean \pm SEM $(n=8) .{ }^{* *} P<0.001 ; 2$-way ANOVA with Tukey's test. (E) Representative images of H\&E staining of the pancreata $(n=8)$. Scale bars: $300 \mu \mathrm{m}$. (F) Histology score evaluation of AP. Mean \pm SEM $(n=8)$. ${ }^{* * *} P<0.001$; 2-way ANOVA with Tukey's test. (C) Representative immunohistochemical staining for CD11b (pan leukocytes), F4/80 (macrophage), and Gr-1 (neutrophil) positive inflammatory cells (brown signal with hematoxylin purple counterstain) on sections from transgenic PRSS1 ${ }^{\mathrm{R} 122 \mathrm{H}}$ mice and $\mathrm{C57BL} / 6$ ) mice 24 hours after cerulein induction $(n=8)$. Scale bars: $200 \mu \mathrm{m}$. (H) Immunohistochemical staining for analysis of p65 nuclear translocation, an indicator of NF- $\kappa B$ activation in the pancreata of PRSS1 ${ }^{\mathrm{R} 122 \mathrm{H}}$ mice and C57BL/6) mice $(n=8)$. Scale bars: $200 \mu \mathrm{m}$. (I) Quantification of p65 nuclear translocation in the pancreata of $\mathrm{PRSS1}^{\mathrm{R} 122 \mathrm{H}}$ mice and C57BL/6J mice. Mean $\pm \operatorname{SEM}(n=8)$. ${ }^{* *} P<0.001 ; 2$-way ANOVA with Tukey's test. (J) Pancreatic mRNA expression levels of monocyte chemoattractant protein-1 (Mcp1), tumor necrosis factor alpha (Tnfa), interleukin 1 $1 /(11 b)$, and $/ 16$ in PRSS1R122H mice and C57BL/6) mice were measured by real-time RT-PCR. Mean \pm SEM $(n=4) .{ }^{*} P<0.05 ;{ }^{* *} P<0.001 ; 2$-way ANOVA with Tukey's test. 
A
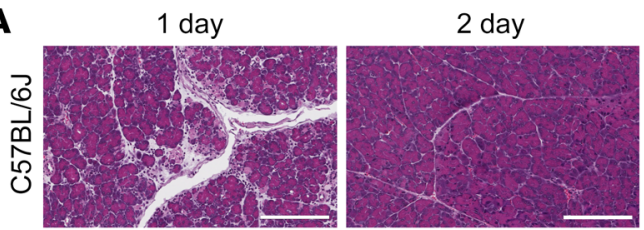

3 day

7 day
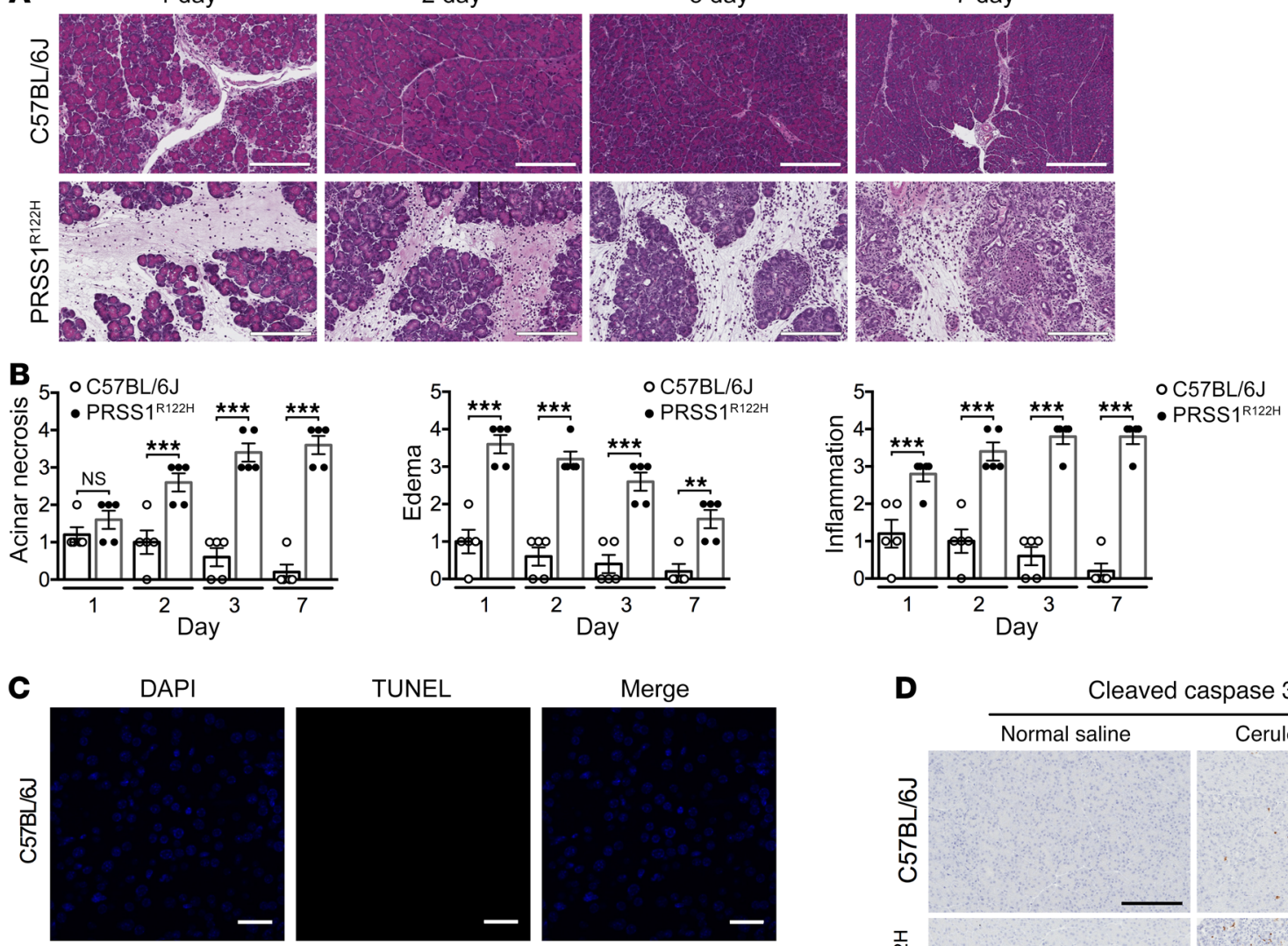

TUNEL
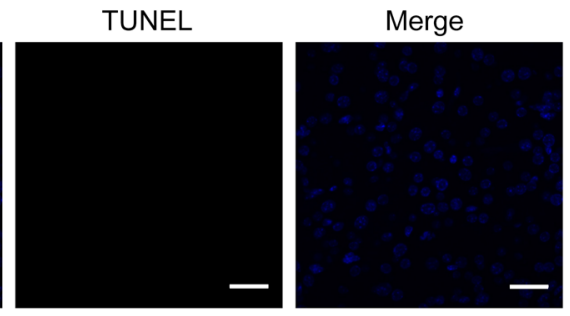

D

Cleaved caspase 3
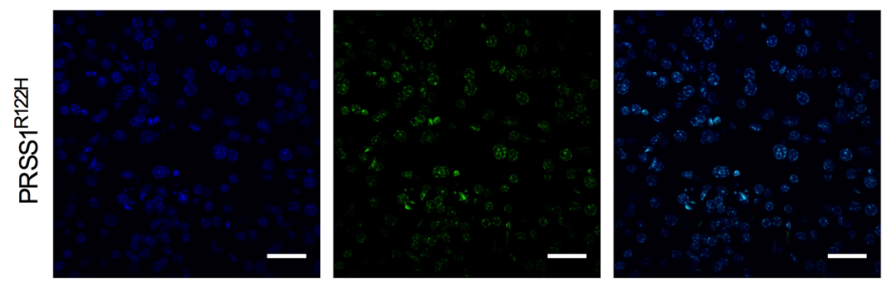

E
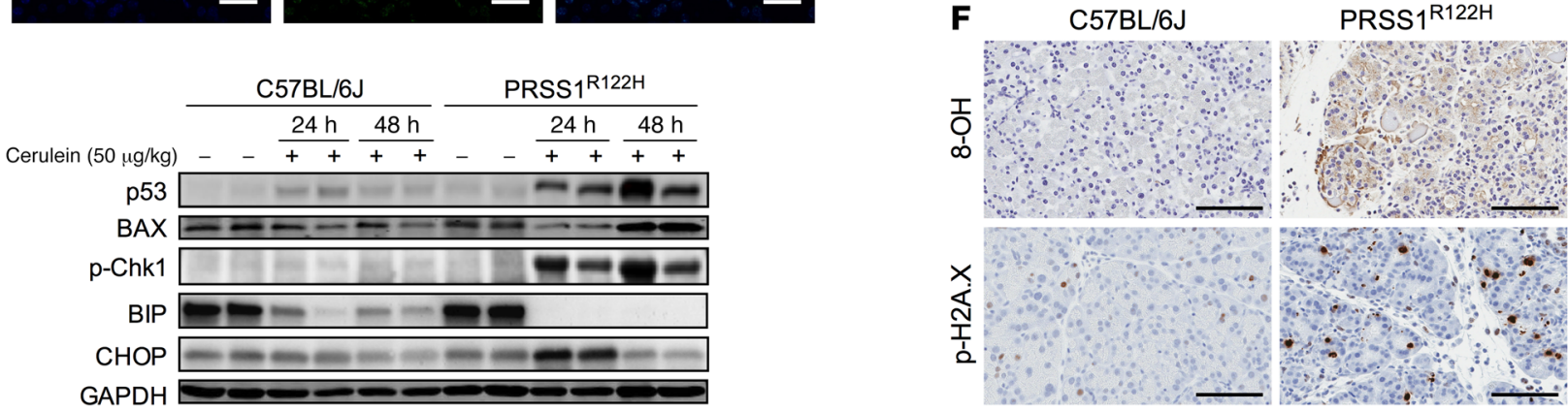

G

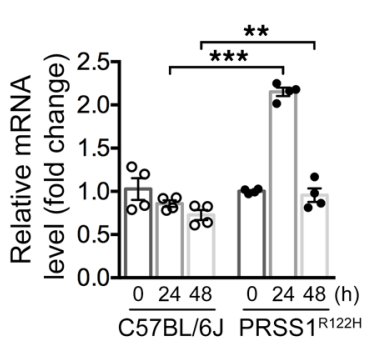

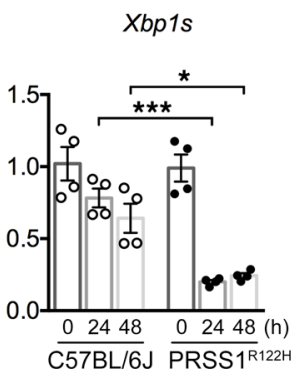
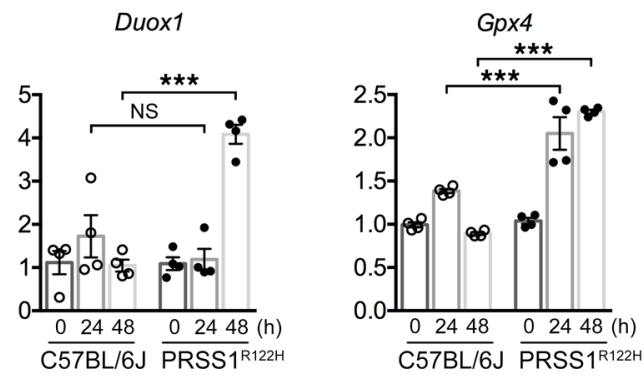
Figure 3. Progressive pancreatic damage and activation of stress signaling pathways in PRSS1 ${ }^{\mathrm{R} 122 \mathrm{H}}$ mice. (A) H\&E staining showed progressive pancreatic damage on sections from transgenic PRSS1 ${ }^{\mathrm{R} 22 \mathrm{H}}$ mice after cerulein-induced AP. In contrast, similarly treated C57BL/6) mice recovered fully (representative of 5 independent samples). Scale bars: $400 \mu \mathrm{m}$. (B) Acinar cell death, pancreatic edema, and inflammation evaluation in AP after cerulein induction. Mean $\pm \operatorname{SEM}(n=5) .{ }^{* *} P<0.01$; ${ }^{* *} P<0.001$; 2-tailed unpaired Student's $t$ test. (C) Using TUNEL staining, extensive pancreatic acinar cell apoptosis was detected in transgenic $\mathrm{PRSS1}^{\mathrm{R} 122 \mathrm{H}}$ mice after cerulein induction. In contrast, pancreatic acinar cell apoptosis in [57BL/6] mice was much less prevalent (representative of 5 independent samples). Scale bars: $200 \mu \mathrm{m}$. (D) Cleaved caspase 3 was upregulated in the pancreatic acinar cells of PRSS1 ${ }^{\mathrm{R} 122 \mathrm{H}}$ mice (representative of 5 independent samples). Scale bars: $200 \mu \mathrm{m}$. (E) Western blot showed higher levels of p53 and its target gene BAX, DNA damage signaling p-CHK1, and abnormal ER stress-related proteins Bip and CHOP in the pancreata of $\mathrm{PRSS1}^{\mathrm{R} 122 \mathrm{H}}$ mice than in those from $\mathrm{C57 \textrm {BL } / 6 ]}$ mice. Representative blots from 3 independent assays are shown. (F) Immunohistochemical staining for 8-hydroxy-2'-deoxyguanosine (8-OH) and phospho-Histone H2A.X (Ser139) (p-H2A.X) indicated the presence of DNA damage in the pancreata of PRSS1 ${ }^{\mathrm{R} 122 \mathrm{H}}$ mice. Representative of 5 independent samples. Scale bars: $200 \mu \mathrm{m}$. (G) mRNA levels of endoplasmic reticulum stress-related signaling molecules Atf4 (activating transcription factor 4) and Xbp1s (X-boX binding protein 1 spliced), and ROS-related enzymes Duox1 (dual oxidase 1) and Gpx4 (glutathione peroxidase 4) were measured by real-time RT-PCR. Mean \pm SEM $(n=4) .{ }^{*} P<0.05$; ${ }^{* *} P<0.01 ;{ }^{* *} P<0.001 ; 2$-way ANOVA with Tukey's multiple comparisons test.

Progressive pancreatic damage and activation of cellular stress signaling in PRSS1 ${ }^{R 122 H}$ mice. In humans, edematous AP usually resolves within 1 to 2 weeks; however, in patients with mutant PRSS1 $^{\mathrm{R} 122 \mathrm{H}}$ expression, AP occurs recurrently and inevitably advances to CP. Similarly, cerulein injections caused mild AP in $\mathrm{C} 57 \mathrm{BL} / 6 \mathrm{~J}$ mice, which fully recovered in a few days (Figure $3 \mathrm{~A})$. However, in PRSS1 ${ }^{\mathrm{R} 122 \mathrm{H}}$ mice, cerulein-induced AP failed to resolve (Figure 3A) and was accompanied by severe edema, progressive increase of acinar cell death, and inflammatory cell infiltration (Figure 3B and Supplemental Figure 5A). TUNEL (terminal deoxynucleotidyl transferase dUTP nick-end labeling) and cleaved caspase 3 immunohistochemistry revealed massive acinar cell apoptosis (Figure 3, C and D). Next, we aimed to investigate the potential cellular signaling pathways which led to acinar cell apoptosis. The tumor suppressor p53 integrates multiple stress signals into a series of diverse antiproliferative responses. One of the most important functions of p53 is its ability to induce cell apoptosis (35). A higher level of p53 expression was detected in the pancreata of $\mathrm{PRSS}^{\mathrm{R} 122 \mathrm{H}}$ mice compared with $\mathrm{C} 57 \mathrm{BL} / 6 \mathrm{~J}$ mice (Figure 3E). The p53 target gene, Bcl-2-associated X protein (Bax), which mediates the p53-dependent apoptotic response (36), was also dramatically increased (Figure 3E). DNA damage response is a key mechanism to upregulate p53 expression (37). Indeed, we observed a dramatic increase in DNA damage as assessed by phospho-Histone $\gamma$-H2AX (Ser139) and 8-hydroxy-2'-deoxyguanosine (8-OH-dG or 8-OH) levels in the PRSS1 ${ }^{\mathrm{R} 122 \mathrm{H}}$ mice (Figure $3 \mathrm{~F}$ ). The upregulation of phosphorylated DNA damage-associated signaling molecule CHK1 (Ser345) further indicated that DNA damage signaling pathways were activated (Figure 3E).

We previously observed that active trypsin can cause endoplasmic reticulum (ER) stress $(38,39)$. ER stress and the generation of reactive oxygen species (ROS) are fundamental compo- nents of unchecked unfolded protein response (UPR) (40, 41). In our initial study, ER stress signaling pathways (Bip, CHOP, $\mathrm{XBP} 1 \mathrm{~s}, \mathrm{ATF} 4)$ and enzymes involved in the production of ROS (DUOX1 and GPX4) were dysregulated in the pancreata of mutant PRSS1 $^{\mathrm{R} 122 \mathrm{H}}$ mice (Figure 3, E and G). Whether ER stress and associated ROS production contribute to DNA damage in the context of PRSS1 mutation requires further investigation.

$C P$, resembling histologic features of human $H P$, developed in $P R S S 1^{R 122 H}$ mice. Our data also demonstrated that after initiation of AP, pancreatic stellate cells were activated with upregulation of alpha smooth muscle actin ( $\alpha$-SMA) in PRSS1 ${ }^{\mathrm{R} 122 \mathrm{H}}$ mice but not in C57BL/6 mice (Supplemental Figure 5, B and C). We expect that increased inflammation, extended upregulation of damage signaling, and activation of stellate cells by mutant PRSS1 may perpetuate injury to the development of CP. To examine the development of CP, mice were induced with cerulein and sacrificed 70 days after AP induction (Figure 4A). Significant body weight loss in PRSS1 ${ }^{\mathrm{R} 122 \mathrm{H}}$ mice suggested the development of severe AP at an early time point and pancreatic function insufficiency at a later stage (Figure 4B). At 70 days, macroscopically the pancreata of WT C57BL/6J mice were normal, indicating their full recovery from AP. In contrast, all PRSS1 ${ }^{\mathrm{R} 122 \mathrm{H}}$ mice had smaller pancreata (Figure 4, C and D). Histologic examination showed pancreas histology was normal in C57BL/6J mice, whereas PRSS1 ${ }^{\mathrm{R} 122 \mathrm{H}}$ mice developed CP (Figure 4, E and F). Acinar cell loss, fat replacement, fibrosis, and precancerous pancreatic intraepithelial neoplasia (PanIN) lesion formation were evident in PRSS1 ${ }^{\mathrm{R} 122 \mathrm{H}}$ mice (Figure $4 \mathrm{E}$ ). These histopathologic features were similar to those observed in human HP caused by PRSS1 mutations (Figure 4E). Thus, this novel mouse model with the expression of human PRSS1 $1^{\mathrm{R} 122 \mathrm{H}}$ mimics the features of human HP (42).

$P_{R S S 1}{ }^{R 122 H}$ mice were more susceptible to cerulein-induced AP than PRSS1 ${ }^{W T}$ mice. Next, we aimed to discern the specific roles of the $\mathrm{R} 122 \mathrm{H}$ mutation in determining the severity of pancreatitis and to exclude that the severe pancreatitis, which developed in the PRSS1 ${ }^{\mathrm{R} 122 \mathrm{H}}$ mice, was solely caused by overexpression of PRSS1. For this purpose, we developed a transgenic mouse line with the same bacterial artificial chromosome to express WT human PRSS1 (PRSS1 ${ }^{\mathrm{WT}}$, no R122H mutation) (Figure 5A) and compared the severity of pancreatitis between the PRSS1 ${ }^{\mathrm{WT}}$ mice and PRSS1 ${ }^{\mathrm{R} 122 \mathrm{H}}$ mice. PRSS1 protein expression levels were similar in these transgenic mouse lines (Figure 5B). Initially, trypsinogen activation in response to CCK was measured in primary pancreatic acinar cells isolated from PRSS1 ${ }^{\mathrm{R} 122 \mathrm{H}}$ and $\mathrm{PRSS} 1^{\mathrm{WT}}$ mice (Figure 5C). Our data indicated that pancreatic acinar cells from $\mathrm{PRSS}^{\mathrm{R} 122 \mathrm{H}}$ mice were more sensitive to lower concentrations of CCK stimulation (Figure 5C). Next, PRSS1 ${ }^{\mathrm{R} 122 \mathrm{H}}$ and $\mathrm{PRSS}^{\mathrm{WT}}$ mice were administrated with a single i.p. injection of cerulein at various doses and pancreatitis was evaluated 24 hours after injection. We found that PRSS1 ${ }^{\mathrm{R} 122 \mathrm{H}}$ mice developed more severe pancreatitis at lower doses of cerulein than PRSS1 ${ }^{\text {WT }}$ mice as manifested by increased pancreatic edema (Figure 5D), elevated serum amylase levels (Figure 5E), and histologic pancreatic inflammation (Figure 5, F and G). These data confirmed that the R122H mutation of PRSS1 did sensitize transgenic mice to the development of AP more severe than PRSS1 ${ }^{\mathrm{WT}}$ mice and provides an explanation why human patients with PRSS1 R122H mutation are more prone to 
A Cerulein $(50 \mu \mathrm{g} / \mathrm{kg}) \mathbf{v} 6 \times$
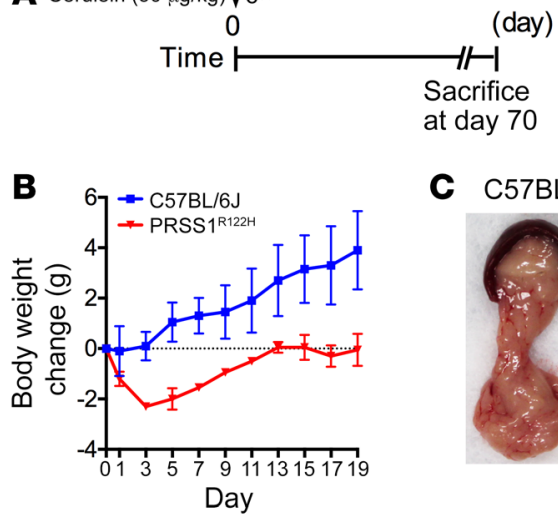

C C57BL/6J PRSS1R122H
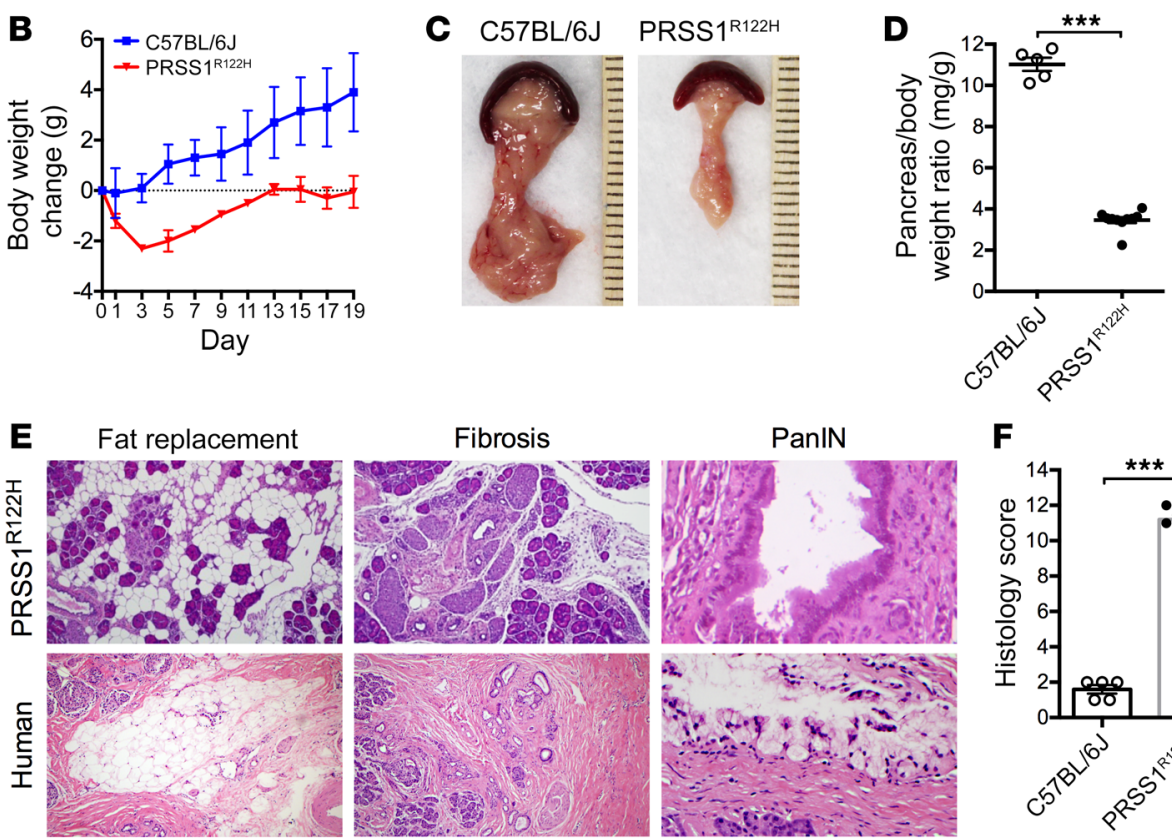

F

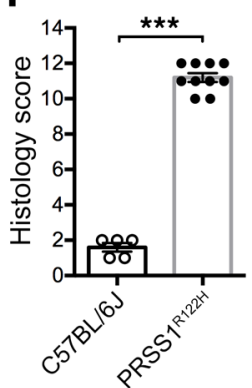

Figure 4. CP developed in transgenic PRSS1 ${ }^{\text {R122H }}$ mice. (A) Schema of cerulein administration protocol. (B) After cerulein induction, the body weight changes of the mice were monitored. Mean \pm SEM ( $n=$ 5-10). (C) Representative pancreas images on day 70 from transgenic PRSS1 ${ }^{1222 \mathrm{H}}$ mice and WT C57BL/6) mice ( $n=5-10)$. (D) Pancreas weight was compared 70 days after cerulein induction. Mean \pm SEM $(n=5-10)$. ${ }^{* * *} P<0.001$; 2-tailed unpaired Student's $t$ test. (E) CP with fat replacement, fibrosis, and pancreatic intraepithelial neoplasia (PanIN) lesions developed in PRSS1 ${ }^{\text {R122H }}$ mice. These features were similarly observed in the pancreata of human patients with hereditary pancreatitis. (F) Overall histology score of CP. Mean \pm SEM $(n=5-10) .{ }^{* *} P<0.001 ; 2$-tailed unpaired Student's $t$ test. the development of AP. However, at maximum stimulation both $\mathrm{PRSS}^{\mathrm{WT}}$ mice and PRSS1 ${ }^{\mathrm{R} 122 \mathrm{H}}$ mice produced the same amount of trypsin. With maximum stimulation, the severity of AP was also similar between these mice (Figure 5, D-G). These observations suggest that trypsin activity also determines the severe of AP in patients with WT RPSS1 when the etiology factors are robust.

Increased trypsin activity was the cause of more severe pancreatitis in $P R S S 1^{R 122 H}$ mice. In vitro biochemical studies have shown that gain-of-function PRSS1 mutations increase trypsinogen autoactivation and/or inhibit trypsinogen degradation (20, 27). The mutations in the PRSS1 gene may also cause trypsinogen protein misfolding, resulting in ER stress (43). To study the nature of the $\mathrm{R} 122 \mathrm{H}$ mutation in the development of $\mathrm{HP}$, we developed another transgenic mouse line using the same construct as the PRSS1 ${ }^{\mathrm{R} 122 \mathrm{H}}$ mice, but they express an enzymatically dead PRSS1 ${ }^{\mathrm{R} 122 \mathrm{H}}$ (Dead$\mathrm{PRSS}^{\mathrm{R} 122 \mathrm{H}}$ or PRSS1 $\left.{ }^{\text {Dead }}\right)$. The Dead-PRSS1 ${ }^{\mathrm{R} 122 \mathrm{H}}$ construct was developed using genetic recombineering technology to introduce an S200T point mutation into the PRSS1 ${ }^{\mathrm{R} 122 \mathrm{H}}$ construct (Figure $6 \mathrm{~A}$ ), which disrupts the catalytic triad of trypsin, thus abolishing its enzymatic activity (44). PRSS1 protein expression levels were similar in each of the transgenic mouse lines (Supplemental Figure 6A). Measurement of total trypsin capacity after activating trypsinogen in the pancreas lysate with enteropeptidase showed that trypsin capacity was increased by nearly 2 folds in PRSS1 ${ }^{\mathrm{R} 122 \mathrm{H}}$ and PRSS1 $^{\text {WT }}$ mice (Supplemental Figure 6B). However, the trypsin capacity in Dead-PRSS1 ${ }^{\mathrm{R} 122 \mathrm{H}}$ mice was similar to that of $\mathrm{C} 57 \mathrm{BL} / 6$ mice (Supplemental Figure 6B), suggesting that transgenic expression of Dead-PRSS1 ${ }^{\mathrm{R} 122 \mathrm{H}}$ did not increase trypsin activity levels in these mice. In consistent with these findings, cerulein increased more trypsin activity in PRSS1 ${ }^{\mathrm{R} 122 \mathrm{H}}$ mice but not in Dead-PRSS1 $1^{\mathrm{R} 122 \mathrm{H}}$ mice (Figure 6B). To investigate the effects of Dead-PRSS1 $1^{\mathrm{R} 122 \mathrm{H}}$ expression on the severity of pancreatitis, AP was induced by injections of cerulein (Figure 6C). Compared with the severe pancreatitis observed in PRSS1 ${ }^{\mathrm{R} 122 \mathrm{H}}$ mice, the Dead-PRSS1 ${ }^{\mathrm{R} 122 \mathrm{H}}$ mice showed only mild inflammation, which is similar to WT mice (Figure 6, D-H), indicating that enzymatically dead $\mathrm{PRSS}^{\mathrm{R} 122 \mathrm{H}}$ completely abolished the severe pancreatitis caused by the PRSS1R122H mutation. Furthermore, 7 days after cerulein induction of AP (Figure 6I) all PRSS1 ${ }^{\mathrm{R} 122 \mathrm{H}}$ mice developed CP (Figure 6, J-L) with pancreatic atrophy (Figure 6, J and $\mathrm{K}$ ) and chronic inflammation (Figure 6L). In stark contrast, the pancreas size and histologic findings in the Dead-PRSS1 $1^{\mathrm{R} 122 \mathrm{H}}$ mice were normal (Figure 6, J-L). Collectively, these results strongly support the idea that the $\mathrm{R} 122 \mathrm{H}$ mutation of PRSS1 causes severe pancreatitis through increased trypsin activity, not through ER stress due to protein misfolding. The ER stress signaling observed in the PRSS1 ${ }^{\mathrm{R} 122 \mathrm{H}}$ mice is likely related to increased trypsin activity, as shown previously (38). The importance of trypsin in pancreatitis was also supported by other transgenic mouse models, even though the mutations of trypsinogen used in those models are not present in human $\operatorname{HP}(38,45)$.

An experimental therapeutic study with $P R S S 1^{R 122 H}$ mice discovered a novel therapy for hereditary pancreatitis. Currently there are no targeted preventive or therapeutic interventions for pancreatitis. Our newly established humanized model of pancreatitis may offer the opportunity for preclinical evaluation of novel therapies. Because our studies have shown that trypsin activity has a critical role in the pathogenesis of pancreatitis, we aimed to test the effects of trypsin inhibition on the severity of pancreatitis. We chose to test a specific trypsin inhibitor, camostat mesylate (trypsin Ki $37 \mathrm{nM}$, thrombin Ki $570 \mathrm{nM}$ ), which has been used to treat 
A

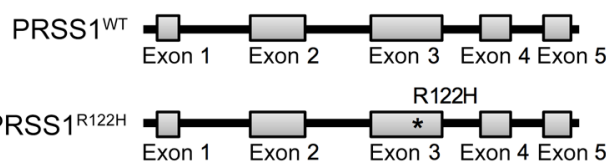

B

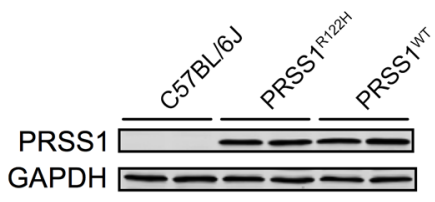

C

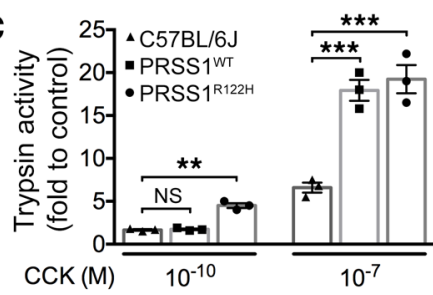

D

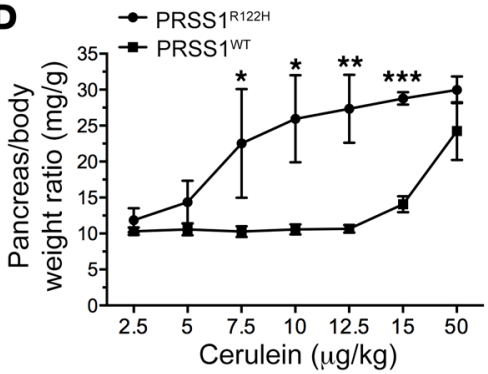

E

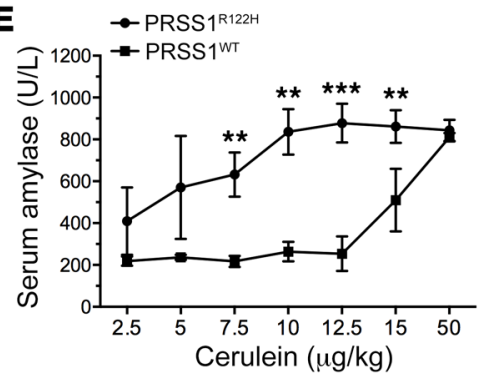

$\mathbf{F}$

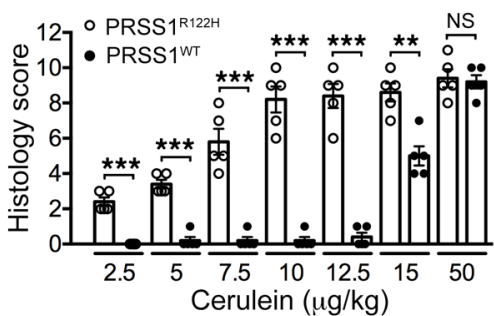

G

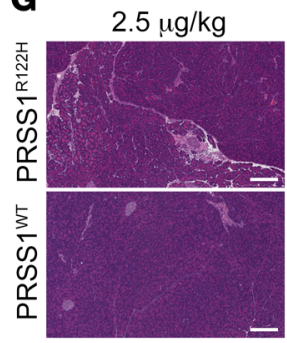
$5.0 \mu \mathrm{g} / \mathrm{kg}$

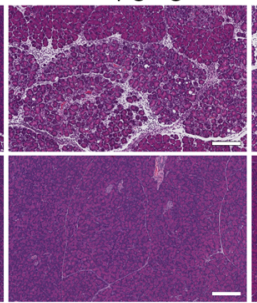

$7.5 \mu \mathrm{g} / \mathrm{kg}$

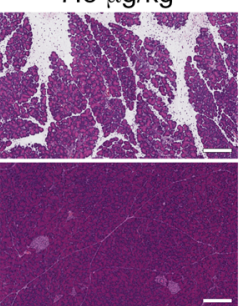

$10.0 \mu \mathrm{g} / \mathrm{kg}$

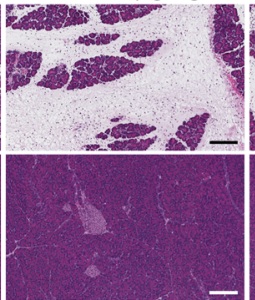

$12.5 \mu \mathrm{g} / \mathrm{kg}$

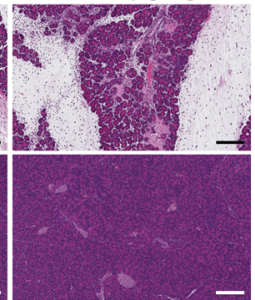

$15.0 \mu \mathrm{g} / \mathrm{kg}$

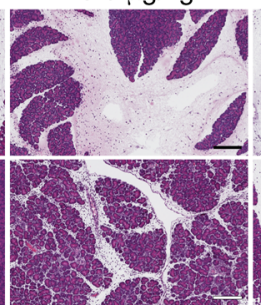

$50 \mu \mathrm{g} / \mathrm{kg}$

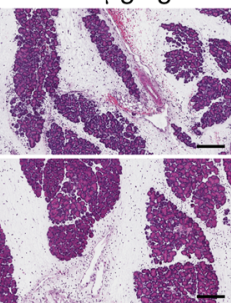

Figure 5. PRSS1 ${ }^{\mathrm{R} 122 \mathrm{H}}$ mice were more sensitive to induction of pancreatitis than were PRSS1 ${ }^{\mathrm{WT}}$ mice. (A) Transgenic mice expressing WT human PRSS1 $\left(\right.$ PRSS1 $^{\mathrm{WT}}$ ) were generated for comparison with PRSS1 ${ }^{R 122 \mathrm{H}}$ mice. (B) Western blot showed similar expression levels of PRSS1 in these transgenic mice. Representative blots from 3 independent assays are shown. (C) Pancreatic acinar cells were isolated from the indicated mice and trypsinogen activation in response to low and high concentrations of CCK was measured. Mean $\pm \operatorname{SEM}(n=3)$. ${ }^{* *} P<0.01 ;{ }^{* * *} P<0.001 ; 1$-way ANOVA with Tukey's multiple comparisons test. (D) Greater pancreatic edema (pancreas-to-body weight ratio) was seen in PRSS1 ${ }^{R 122 \mathrm{H}}$ mice compared with PRSS1 ${ }^{\mathrm{WT}}$ mice at 24 hours after a single-dose of cerulein. The cerulein dose ranged from $2.5 \mu \mathrm{g} / \mathrm{kg}$ to $50 \mu \mathrm{g} / \mathrm{kg}$. Mean \pm SEM $(n=5) .{ }^{*} P<0.05 ;{ }^{* *} P<0.01 ;{ }^{* *} P<0.001 ; 1$-way ANOVA with Tukey's multiple comparisons test. (E) Greater serum amylase levels were seen in PRSS1 ${ }^{122 H}$ mice than in PRSS1WT mice. Mean \pm SEM $(n=5)$. ${ }^{*} P<0.05$; ${ }^{* *} P<0.01 ;{ }^{* *} P<0.001 ; 1$-way ANOVA with Tukey's multiple comparisons test. (F) Overall histology score of AP developed after various doses of cerulein insults. Mean \pm SEM $(n=5) .{ }^{* *} P<0.01 ;{ }^{* *} P<0.001 ; 1$-way ANOVA with Tukey's multiple comparisons test. (G) Representative H\&E staining showed that $\mathrm{PRSS1}^{\mathrm{R} 122 \mathrm{H}}$ mice were more sensitive to cerulein-induced AP than were PRSS1 ${ }^{\mathrm{WT}}$ mice $(n=5)$. Scale bars: $200 \mu \mathrm{m}$.

CP in Japan (Foipan; Ono Pharmaceutical Co, Ltd.) but has not been approved for use in the United States. We also included the anticoagulant dabigatran (Pradaxa; Boehringer Ingelheim Pharmaceuticals, Inc.), which is primarily used as a thrombin inhibitor (Ki $4.5 \mathrm{nM}$ ) but also inhibits trypsin activity (Ki $50 \mathrm{nM}$ ). After initiation of AP by 5 injections of cerulein administered every hour, camostat or dabigatran was introduced and administered twice daily over a period of 7 days (Figure 7A). This strategy mimics a therapeutic scenario in the clinic since it typically takes a few hours after the onset of pancreatitis for patients to reach a hospital and start treatment. In untreated controls, pancreata shrank and showed histologic manifestations of CP. Camostat moderately protected the pancreas from CP at higher doses (Figure 7, B-D). Surprisingly, dabigatran nearly completely abolished the progression of CP (Figure 7, B-D), outperforming the more selective and stronger-affinity trypsin inhibitor camostat. We reasoned that the anticoagulation properties of dabigatran may contribute to its beneficial effects on reducing the severity of pancreatitis.

In the clinic, some patients with AP may be diagnosed late. To investigate whether dabigatran will still be effective in these cases, we performed an experimental therapeutic study 20 hours after cerulein induction. Our data showed that dabigatran administration preserved the pancreas as compared with untreated mice but to a lesser extent than those treated from 5 hours after cerulein administration (Supplemental Figure 7), suggesting that timely treatment is important for maximum efficacy.

A majority of patients with AP do not harbor PRSS1 mutations. To examine whether dabigatran will be able to prevent the development of AP in mice with WT PRSS1, we tested the effects of dabigatran in PRSS1 ${ }^{\mathrm{WT}}$ transgenic mice. Dabigatran treatment successfully prevented the development of AP in PRSS1 ${ }^{\mathrm{WT}}$ mice (Supplemental Figure 8), suggesting dabigatran is not selective for mutant PRSS1, and its beneficiary therapeutic benefit can be extended to encompass a variety of patients with AP.

Anticoagulation and trypsin inhibition synergistically improved pancreatitis. The existence of extensive cross-talk between coagulation and inflammation pathways has long been recognized (46). Inflammation can upregulate coagulation factors and cause hypercoagulation (47). Conversely, coagulation factor complexes stimulate protease activated receptor signaling, which induces the release of inflammatory cytokines and have important roles in pancreatitis and many other inflammatory diseases (48-52). 
A

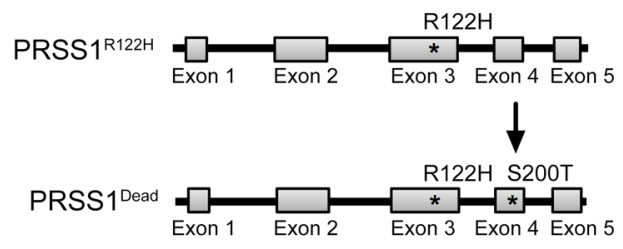

D
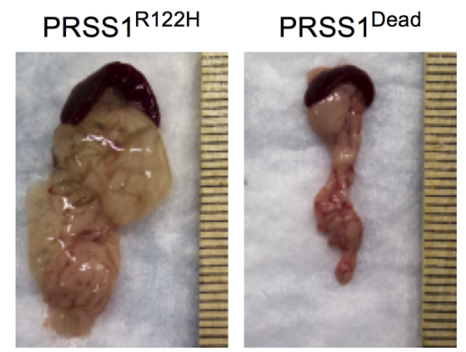

G
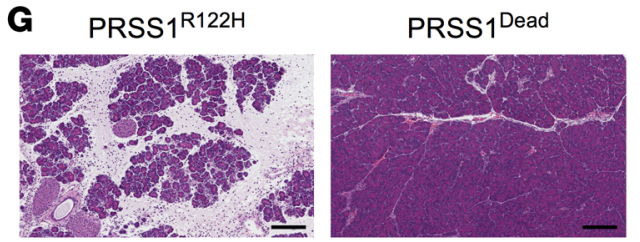$$
\mathbf{J}
$$

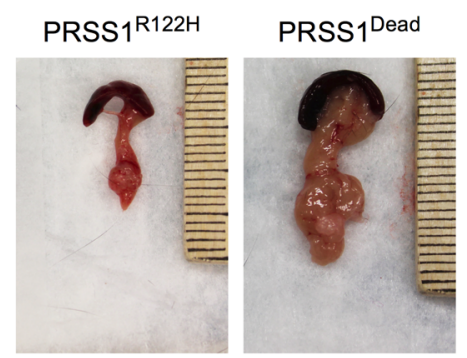

B

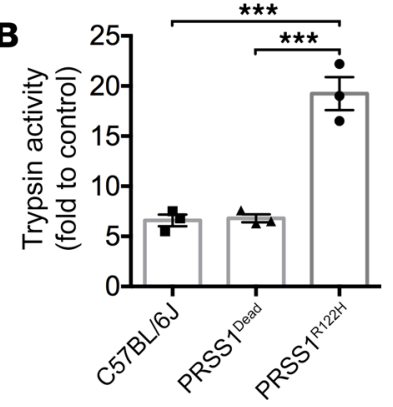

E

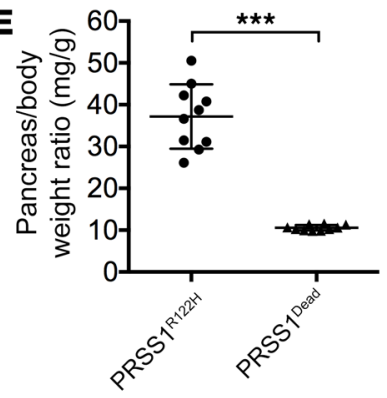

H

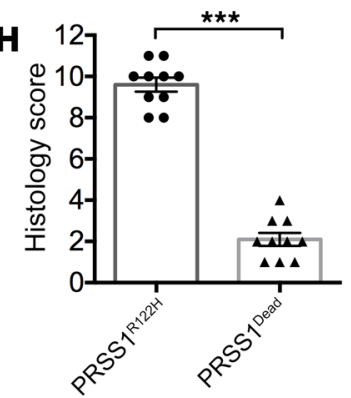

K

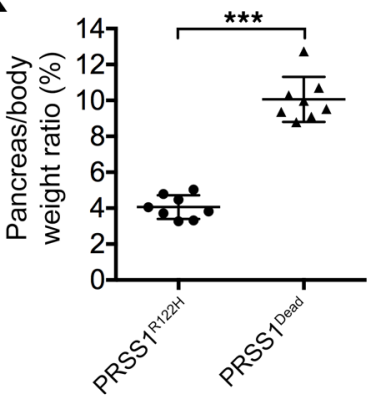

C

Cerulein $(50 \mu \mathrm{g} / \mathrm{kg}) \boldsymbol{\Downarrow} \boldsymbol{\Downarrow} \boldsymbol{\Downarrow} \boldsymbol{\Downarrow} \boldsymbol{\Downarrow}$

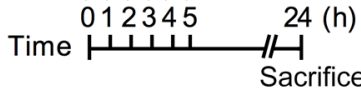

$\mathbf{F}$

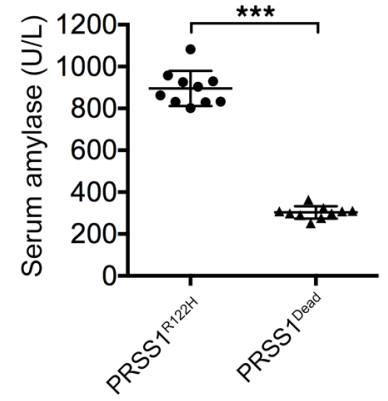

I

Cerulein $(50 \mu \mathrm{g} / \mathrm{kg}) \downarrow \Downarrow \Downarrow \downarrow \downarrow \downarrow \downarrow$

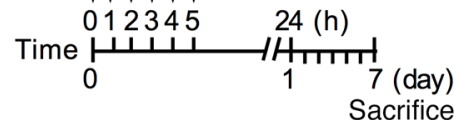

$\mathbf{L}$

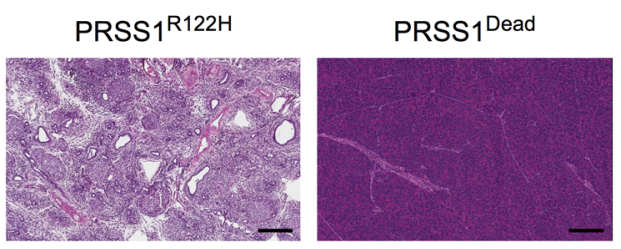

Figure 6. Increased trypsin activity was the cause of severe pancreatitis in PRSS1 ${ }^{122 H}$ mice. (A) Enzymatically inactive Dead-PRSS1 ${ }^{\text {R222H }}$ (PRSS1 ${ }^{\text {Dead }}$ ) transgene construct was developed by introducing a S200T point mutation into PRSS1R122H using recombineering technology. (B) In response to cerulein, Dead-PRSS1 ${ }^{122 \mathrm{H}}$ generated the same amount of active trypsin as C57BL/6 mice. Mean \pm SEM $(n=3) .{ }^{* * *} P<0.001 ; 1$-way ANOVA with Tukey's test. (C) Schema of cerulein-induced AP in PRSS1 ${ }^{\text {Dead }}$ and PRSS1 $1^{\mathrm{R} 122 \mathrm{H}}$ mice. (D) Enlarged pancreata were observed in PRSS1 ${ }^{\mathrm{R} 122 \mathrm{H}}$ mice but not in PRSS10ead mice 24 hours after cerulein induction $(n=10)$. (E) Comparison of pancreatic edema (pancreas-to-body weight ratio) 24 hours after cerulein induction. Mean \pm SEM $(n=10) .{ }^{* *} P<0.001 ; 2$-tailed unpaired Student's $t$ test. $(\mathbf{F})$ Comparison of serum amylase level 24 hours after cerulein induction. Mean \pm SEM $(n=10)$. ${ }^{* * *} P<0.001 ; 2$-tailed unpaired Student's $t$ test. (C) Cerulein caused more severe AP in PRSS1 ${ }^{\text {R122H }}$ mice than in PRSS1Dead mice. Representative images of H\&E staining 24 hours after cerulein induction are shown $(n=10)$. Scale bars: $200 \mu \mathrm{m}$. (H) Overall histology score of AP from PRSS1R122H mice and PRSS1 ${ }^{\text {Dead }}$ mice. Mean \pm SEM $(n=10)$. ${ }^{* *} P<0.001 ; 2$-tailed unpaired Student's $t$ test. (I) To investigate cerulein-induced CP in PRSS1R122H and PRSS1 ${ }^{\text {Dead }}$ mice, the mice were sacrificed 7 days after cerulein induction. (J) Seven days after cerulein induction, all the pancreata from PRSS1 ${ }^{122 \mathrm{H}}$ mice shrank (indicating CP), but all the pancreata from PRSS1 ${ }^{\text {Dead }}$ mice appeared to be normal $(n=8)$. (K) The pancreas-to-body weight ratio 7 days after cerulein indicated that the pancreata in PRSS1 ${ }^{\mathrm{R} 122 \mathrm{H}}$ mice were much smaller than those in PRSS1Dead mice. Mean $\pm \mathrm{SEM}(n=8)$. ${ }^{* *} P<0.001$; 2-tailed unpaired Student's $t$ test. (L) At day 7, histologic examination (H\&E staining) demonstrated chronic damage in PRSS1 ${ }^{\mathrm{R} 122 \mathrm{H}}$ mice, whereas the pancreata of PRSS1 ${ }^{\text {Dead }}$ mice were normal $(n=$ 8). Scale bars: $200 \mu \mathrm{m}$. 
A Cerulein $(50 \mu \mathrm{g} / \mathrm{kg}) \downarrow \downarrow \downarrow \downarrow \downarrow \downarrow \downarrow$

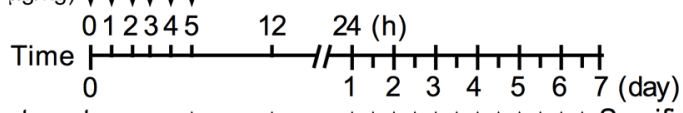

Drug treatment
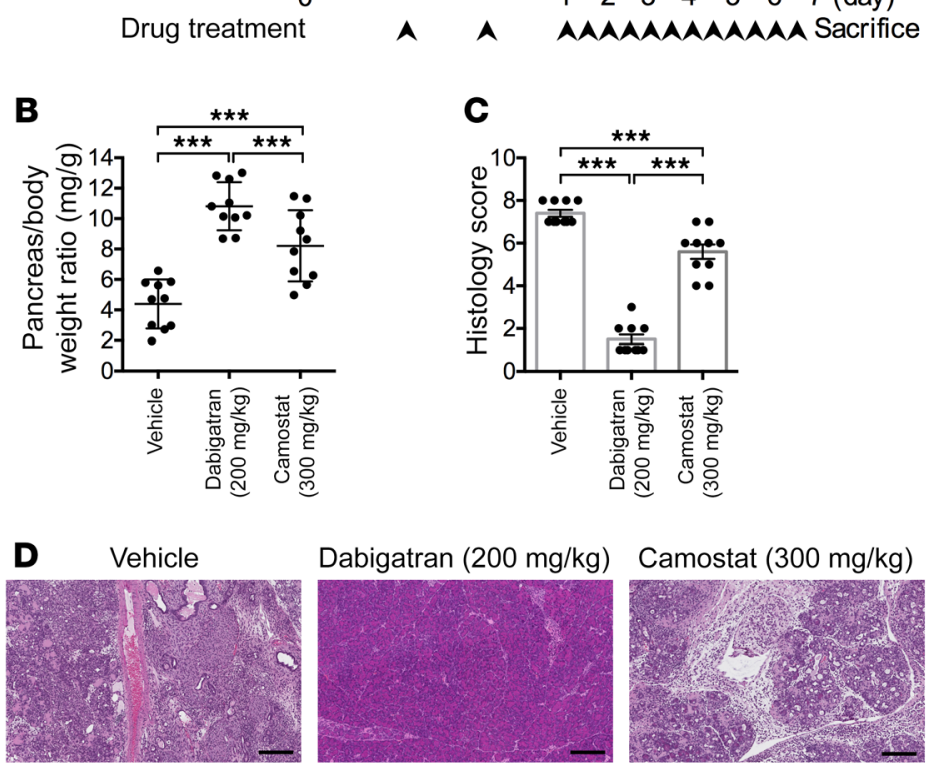

Figure 7. Effective experimental therapeutics with an FDAapproved anticoagulation agent in PRSS1 ${ }^{\mathrm{R} 122 \mathrm{H}}$ mice. (A) Schema of pancreatitis induction and treatment in PRSS1 ${ }^{\mathrm{R} 122 \mathrm{H}}$ mice. Pancreatitis was induced by cerulein, and therapeutic drugs were administered 5 hours after the first cerulein injection. (B) After 7 days of treatment, pancreata in the untreated control group became smaller. In contrast, pancreata in dabigatran-treated groups were mostly normal. Camostat only exhibited intermediate effects at higher does (300 $\mathrm{mg} / \mathrm{kg}$ ). Both drugs were given twice daily for 7 days. Mean \pm SEM ( $n=10$ per group). ${ }^{* *} P<0.001 ; 1$-way ANOVA with Tukey's multiple comparisons test. (C) Histology score evaluation showed that dabigatran significantly improved CP. Mean $\pm \mathrm{SEM}$ ( $n=10$ per group). ${ }^{* *} P$ $<0.001$; 1-way ANOVA with Tukey's multiple comparisons test. (D) Representative images of H\&E staining after drug treatments over 7 days ( $n=10$ per group). Scale bars: $200 \mu \mathrm{m}$.
Therefore, the reciprocal interactions between coagulation and inflammation may form a positive feedback loop that can result in progressive tissue damage (53). Consistent with this mechanism, in our animal model we also observed increased fibrin deposition (Figure 8A) in the intercellular spaces and active thrombin expression (Figure 8B), indications of activated coagulation in the pancreas. Yet, clinical trials showed that using anticoagulation drugs alone had only limited benefits $(54,55)$. It is likely that both trypsin and coagulation are fundamental mechanisms in the progression of CP and must be targeted simultaneously for the best effect.

To test this hypothesis we used the trypsin-specific inhibitor camostat, as well as a Factor Xa-specific anticoagulation agent apixaban (Eliquis; Bristol-Myers Squibb Company) (Ki for Factor Xa $0.25 \mathrm{nM}$, trypsin $>20,000 \mathrm{nM}$ ), either alone or in combination (Figure 8C). As shown in Figure 8, D-F, camostat and apixaban alone provided limited protection against pancreatitis; however, the combination of these 2 inhibitors significantly improved pancreatitis in these mice. The synergistic effects of antitrypsin combined with anticoagulation therapy were further validated using camostat in combination with 2 other specific anticoagulants (Supplemental Figure 9). Collectively, the data suggest that targeting both trypsin and coagulation pathways is required for effective pancreatitis therapy.

\section{Discussion}

In this study, we generated several transgenic mice to express human WT PRSS1 and its mutant derivatives. Mice with human HP-related PRSS1 ${ }^{\mathrm{R} 122 \mathrm{H}}$ gene expression developed severe AP, which progressed to $\mathrm{CP}$, recapitulating the pathogenesis of human HP. Increased trypsin activity is the key mechanism that makes PRSS1 ${ }^{\mathrm{R} 122 \mathrm{H}}$ mice more susceptible to pancreatitis. With this humanized model of pancreatitis, we further demonstrated that coagulation plays an important role in the pathogenesis of HP.
Inhibition of both trypsin and coagulation, using FDA-approved drugs for other diseases, was able to synergistically prevent the progression of CP. This clinically relevant mouse model and findings obtained from this study will be informative for immediate clinical trials, encourage the further investigation into its mechanisms, and aid in the development and testing of more effective therapies for human pancreatitis.

Although AP is the most common gastrointestinal diagnosis, $\mathrm{HP}$ is relative rare. It is estimated that the prevalence of $\mathrm{HP}$ in the United States is about 1000 cases, although the actual numbers are not known (http://www.pancreapedia.org/reviews/hereditarypancreatitis). However, patients with the mutations have greater than $80 \%$ penetrance of developing recurrent $\mathrm{AP}$ and $\mathrm{CP}$ with a high risk of pancreatic cancer. Notably, medications that are effective for HP also work for pancreatitis with WT PRSS1. Therefore, these animal models with human PRSS1 expression can be a prototype for general pancreatitis research.

There are practical difficulties associated with obtaining biopsies from the pancreas during early stages of pancreatitis; therefore, our research into the pathophysiology of HP has been greatly limited. An animal model that recapitulates the human disease will provide us with a powerful tool to study its initiation and progression as well as interventions to treat it. Since the discovery that mutations in the PRSS1 gene were linked to the development of HP in 1996 (19, 20, 22, 23), many previous attempts to develop such an animal model by mimicking the mutations harbored in patients with HP led to only limited success $(26,27)$. Therefore, a more sophisticated transgene strategy is required to model this disease.

Based on our experience with genetically engineered mouse models and our recent understanding of the biochemical characteristics of PRSS1, we reasoned that 3 major obstacles previously hindered the successful development of this model. First, the 
A

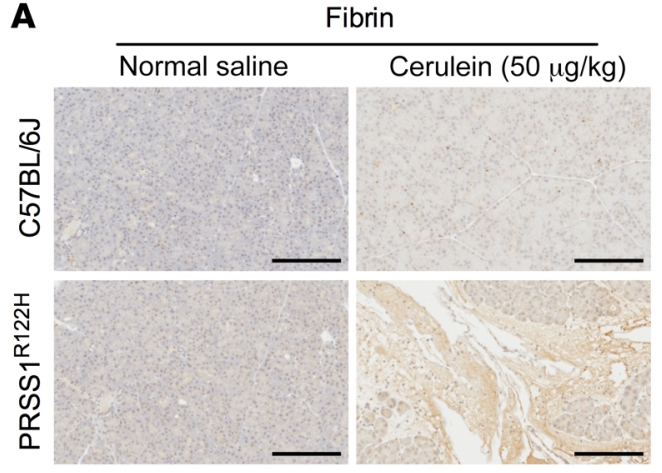

C

Cerulein $(50 \mu \mathrm{g} / \mathrm{kg})$

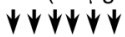

012345

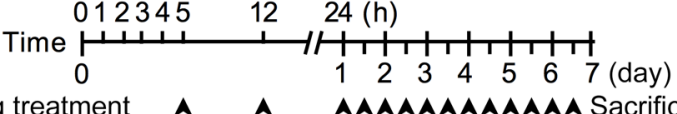

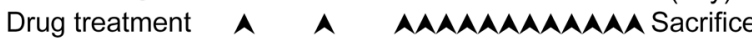

E

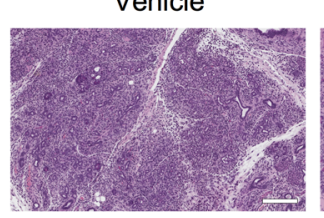

Camostat $(200 \mathrm{mg} / \mathrm{kg})$

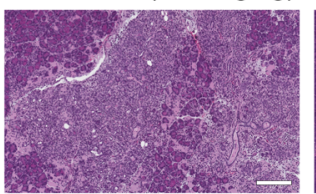

Apixaban $(100 \mathrm{mg} / \mathrm{kg})$

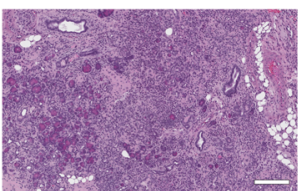

Camostat $(200 \mathrm{mg} / \mathrm{kg})$

+ apixaban $(100 \mathrm{mg} / \mathrm{kg})$

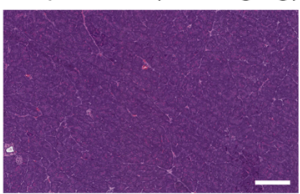

B

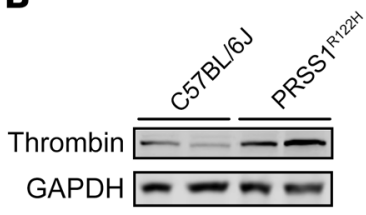

D

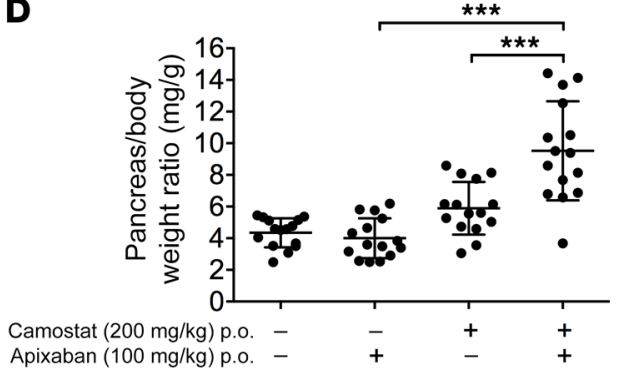

$\mathbf{F}$

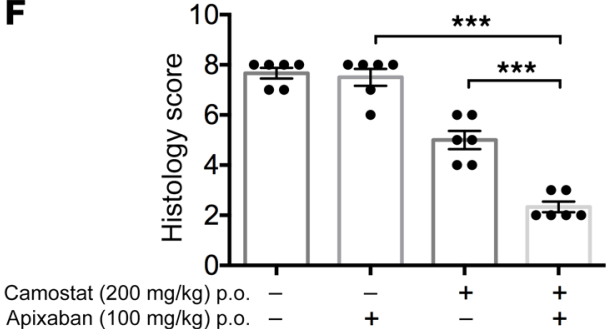

Figure 8. Anticoagulation and trypsin inhibition synergistically improved pancreatitis in PRSS1 ${ }^{\text {R22H }}$ mice. (A) Immunohistochemical analysis showed intrapancreatic fibrin deposition, an indicator of increased coagulation, in the pancreata of PRSS1 ${ }^{\mathrm{R} 122 \mathrm{H}}$ mice 24 hours after cerulein induction $(n=5)$. Scale bars: $200 \mu \mathrm{m}$. (B) Western blot showed that active thrombin significantly increased in the pancreata of PRSS1 ${ }^{\mathrm{R} 12 \mathrm{H}}$ mice compared with those from C57BL/6) mice. Representative blots from 3 independent experiments are shown. (C) Schema of pancreatitis induction and drug treatment with the anticoagulation specific agent (apixaban), trypsin specific inhibitor (camostat), or in combination. Starting 5 hours after pancreatitis induction, drugs were given twice daily by oral gavage over 7 days. (D) Combination of anticoagulation therapy with factor Xa inhibitor apixaban (100 mg/kg) and trypsin inhibitor camostat (200 $\mathrm{mg} / \mathrm{kg}$ ) greatly protected the pancreas, as manifested by preservation of pancreas mass. Mean $\pm \mathrm{SEM}$ ( $n=15$ per group). ${ }^{* * *} P<0.001 ; 1$-way ANOVA with Tukey's multiple comparisons test. (E) Representative histologic images of H\&E staining from untreated, apixaban alone, camostat alone, and combination therapy-treated mice ( $n=15$ per group). Scale bars: $200 \mu \mathrm{m}$. (F) Overall histology score evaluation of the mice. Mean \pm SEM. Representative results from 6 mice per group are shown. ${ }^{* *} P<0.001 ; 1$-way ANOVA with Tukey's multiple comparisons test.

introduction of human PRSS1-equivalent mutations to the mouse form of trypsinogen will not mimic the biochemical phenotype observed in human PRSS1 mutations because of their different autoactivation properties and dissimilar regulation by chymotrypsin C (26-28). Therefore, human PRSS1, instead of mouse Prss1, should be used for transgenic expression. Second, the pancreas is specialized in synthesizing large quantities of digestive enzymes, including PRSS1. Previously, a short elastase gene promoter $(\approx 500$ bp), which lacks many regulatory components, was commonly used to drive the transgenic expression of PRSS1; however it usually gives very low and unstable transgenic expression, as we and others have observed $(56,57)$. Third, the regulatory mechanisms of the PRSS1 promoter are not expected to be the same as those of the elastase gene. Therefore, the native PRSS1 promoter should be used for tight regulation of PRSS1 expression. To solve all these problems in one construct, we introduced the $\mathrm{R} 122 \mathrm{H}$ mutation into a human BAC harboring the full-length human PRSS1 gene with an intact PRSS1 full-length promoter, all exons and introns, and the 3'-UTR for faithful replication of its expression as in humans. With this strategy, transgenic mice expressed the human HP-related gene PRSS1 ${ }^{1122 \mathrm{H}}$ and developed severe AP which progressed to $\mathrm{CP}$, recapitulating many characteristics of the human disease. By comparing with transgenic mice expressing WT PRSS1 and DeadPRSS1 $^{\mathrm{R} 122 \mathrm{H}}$, we established that it is the R122H mutation of PRSS1 that makes the pancreas more susceptible to the development of severe pancreatitis and it is the increased trypsin activity, instead of mutation-caused protein misfolding, that we believe is the root cause of HP. Active trypsin may cause pancreatic acinar cell death through increased ER stress, oxidative DNA damage, upregulated DNA damage signaling, and p53-mediated cell apoptosis. 
At present, there is no proven pharmacologic entity to treat AP. Supportive care with i.v. fluids, bowel rest, and pain control are the mainstays of therapy. The management of CP is extremely challenging, and most patients remain symptomatic with pain, maldigestion, and diabetes, despite therapy. There are no effective procedures to stop the progression or reverse these symptoms (6). Despite the strong experimental evidence showing that trypsin is a key initiator of AP (58-60), more than 70 clinical trials performed over the past 40 years have provided no definitive proof that protease inhibitors alter the course of $\operatorname{AP}(61,62)$. A likely explanation for this inconsistency is that other fundamental mechanisms implicated in the progression of pancreatitis have yet to be discovered.

In recent years, it has been recognized that there is extensive cross-talk between coagulation and inflammation pathways (46, 63). Activation of one system may amplify activation of the other. Inflammation causes endothelial damage, increased fibrinogen concentration, and tissue factor expression on the cell surface of leukocytes, upregulates both platelet count and platelet reactivity, and downregulates anticoagulation factors (47). Conversely, the tissue factor/VIIa complex stimulates PAR-2 signaling, which induces release of inflammatory cytokines $(48,49)$. With the exception of coagulation, factor Xa and thrombin (factor IIa) are also involved in inflammation, predominantly mediated via the activation of proteinase activated receptors (PARs). PAR-1, -3 , and -4 are thrombin receptors. PAR-1 and PAR-2 can be activated by the TF-factor VIIa complex and factor Xa (50). PAR activation plays important roles in pancreatitis and other inflammatory diseases $(51,52)$. Therefore, reciprocal interaction between coagulation and inflammation forms a positive feedback loop which may result in tissue damage or even lethal multi-organ failure - a condition frequently observed in severe AP. Indeed, coagulation abnormalities were observed in $\mathrm{AP}$ and are related to its severity (53). In our animal models, we observed increased active thrombin and fibrin deposition in the intercellular spaces, suggesting abnormal activation of coagulation. Yet, despite the observation that coagulation may play a role in the development of pancreatitis, clinical trials using anticoagulation drugs alone resulted in only limited benefits $(54,55)$.

In an experimental therapeutic endeavor, we used our severe $\mathrm{R} 122 \mathrm{H}$ pancreatitis mouse model to evaluate the preventive and therapeutic significance of several compounds that inhibit the activity of trypsin. These compounds include camostat, which is a selective trypsin inhibitor (trypsin Ki $37 \mathrm{nM}$, thrombin Ki 570 $\mathrm{nM})$, and dabigatran, which is primarily a thrombin inhibitor ( $\mathrm{K} i$ $4.5 \mathrm{nM}$ ), but also exerts the ability to inhibit trypsin activity (Ki 50 $\mathrm{nM})$. In a therapeutic study, each of the drugs was administered once following the last dose of caerulein, then mice were given each of the drugs for an additional 6 days. Interestingly, dabigatran which inhibits both trypsin and coagulation, showed a superior therapeutic potential compared with camostat which only inhibits trypsin. These data suggests that targeting both trypsin inhibition and anticoagulation may be required for effective AP therapy. This hypothesis was strongly supported by the findings that the combination of the trypsin specific inhibitor and anticoagulation specific agents can synergistically improve pancreatitis and prevent its progression to CP. The underlying mechanisms of coagulation pathways in pancreatitis pathogenesis deserve more extensive and intensive investigation in future studies.
In summary, we developed a mouse model that recapitulates the histologic features of human HP. This clinically relevant mouse model and the findings obtained from this study provide justification for clinical trials with the agents studied here.

\section{Methods}

Genetically engineered mice. In a human BAC (clone RP11-701D14, BACPAC Resources, UCSF Benioff Children's Hospital) harboring the full-length human PRSS1 gene with an intact PRSS1 full-length promoter, all exons and introns, and the $3^{\prime}-\mathrm{UTR}$, an $\mathrm{R} 122 \mathrm{H}$ point mutation (PRSS1 ${ }^{\mathrm{R} 122 \mathrm{H}}$ ) was introduced by 2 rounds of genetic targeting using GalK-mediated recombineering (Figure 1A and ref. 29). Briefly, a prokaryotic expression em7-GalK cassette was PCR amplified from plasmid pGalK with R122 GalK F (CCGCATCCAGGTGAGACTGGGAGAGCACAACATCGAAGTCCTGGAGGGGAATGAGCAGTTCATCACCTGTTGACAATTAATCATCGGCA) and R122 GalK R (CGCCAGAGCTCGCAGTGTTGCCCCAGCCAGAGATGAGGCACTTCGTGCCAGTGGCTGGAGGGGCGTCAGCACTGTCCTGCTCCTT), which contain GalK-specific sequences (underlined) and human PRSS1 homologous sequences of exon 3 (italics). The PCR product was introduced into the SW102 strain of Escherichia coli harboring the PRSS1 BAC by electroporation. Successful insertion of the GalK gene into the BAC by recombination was selected using GalK-positive selection medium and further verified by PCR (29). The PRSS1 exon 3 with the $\mathrm{R} 122 \mathrm{H}$ mutation was PCR amplified from a cDNA plasmid with primers R122 cassette F (TGCCTGCCCTGCCCATCAGCCGCATCCAGGTGAGACTG) and R122 cassette R (GACTAAGGGTCCCACTCACCGCCAGAGCTCGCAGTGTTG). The PCR product was used to replace the GalK gene in exon 3 and introduce the R122H mutation. Positive clones were selected using GalK counter-selection medium, which eliminates GalK-positive clones. Successful introduction of $\mathrm{R} 122 \mathrm{H}$ was verified by DNA sequencing.

The Dead-R122H construct was developed using similar GalKmediated recombineering technology to introduce an S200T point mutation into the PRSS1 ${ }^{\mathrm{R} 122 \mathrm{H}}$ construct. The S200T mutation disrupts the trypsin catalytic triad of PRSS1 and thus abolishes its activity (44). The primers used to introduce the GalK gene to exon 5 of BAC-R122H were S200T GalK F (GCTATATTCCTCCTCCAT CTCTCCATACAACTTGTCCCTTCTTCCCCCCAGGGTGACCTGTTGACAATTAATCATCGGCA) and S200T GalK R (GCCATCACCCCAGGAGACAACTCCTTGGAGCTGTCCATTGCAGACCACAGGGCCACTCAGCACTGTCCTGCTCCTT) (homologous arms are in italics and GalK primers are underlined). The S200T mutation was generated with overlapping PCR primers in which TCT (coding serine) was replaced with ACT (coding threonine): S200T F (GTAGCTATATTCСTCСTCCATCTCTCCATACAACTTGTCCCTTCTTCCCCCCAGGGTGATaCTGGTGGCCCTGTGGTCTGC) and S200T R (CAGCCATCACCCCAGGAGACAACTCCTTGGAGCTGTCCATTGCAGACCACAGGGCCACCAGtATCACCCTGGGGGGAAGAAG).

Transgenic mice were developed by pronuclear injection of the BAC clones. Positive transgenes were genotyped by PCR with primers R122 Veri F (CTGTCCATGAGCAGAGAGCTTGAG) and R122 Veri R (CAGTGCAGAGTCTGTGTGTAATG). All the mice were maintained in 12-hour light/12-hour dark cycles with free access to food and water. Sex- and age-matched mice were used in control and experimental groups. Mice, ages 2-8 months old, were used in the experiments unless otherwise specified in the figure legend. No phenotypic differences between sex and ages were noticed in the experiments. 
Cerulein-induced AP model. Cerulein-induced AP models were developed as previously described, with modification (34). Briefly, cerulein (catalog CCKS-001; CPC Scientific) was dissolved in normal saline and administered by i.p. injections at a dose of $50 \mu \mathrm{g} / \mathrm{kg}$ per injection. Twenty-four hours after the first cerulein injection, mice were sacrificed and blood was collected for measurement of serum amylase levels. The pancreas was harvested for the determination of pancreas wet weight-to-body weight ratio as a measure of pancreatic edema or pancreas size.

Experimental therapeutic study. CP was induced by 6 intraperitoneal injections of $50 \mu \mathrm{g} / \mathrm{kg}$ cerulein administered every hour on the first day (34). Seven days after the cerulein injections, mice were humanely euthanized via $\mathrm{CO}_{2}$ inhalation and the pancreas was harvested for histologic and immunohistochemical analysis. For therapeutic studies, mice were randomly assigned into groups and treated by oral administration with vehicle (25\% Captisol in normal saline; catalog RC-0C7-K01; Ligand Pharmaceuticals Inc.) or camostat mesylate (catalog sc-203867; Santa Cruz), dabigatran etexilate mesylate (catalog D100150; Toronto Research Chemicals), apixaban (catalog QC-7598-001; Combi Blocks), Rivaroxaban (catalog QA-2934-001; Combi Blocks), or by i.p. injection with Argatroban (catalog A769000; Toronto Research Chemicals). Drug treatment began 5 hours after the first cerulein injection, twice daily over 7 days. Twelve hours after the final dose, mice were humanely euthanized and pancreata were harvested for analysis.

L-arginine-induced AP model. L-arginine-induced AP models were developed as previously described (64). Briefly, a sterile $8 \%$ (wt/vol) solution of L-arginine was prepared in normal saline and the $\mathrm{pH}$ was adjusted to 7.0; it was then administered intraperitoneally to mice at $4 \mathrm{~g} / \mathrm{kg}$ (twice, at time 0 and 1 hour later). Seventy-two hours after the first L-arginine injection, mice were humanely euthanized and pancreata were harvested for analysis.

Real-time qPCR. Total RNA was extracted from mouse pancreas (30-40 mg tissue) using the RNeasy Plus Mini Kit (Qiagen). RNA ( $1 \mu \mathrm{g})$ was reverse transcribed to complementary DNA using the Go Script RT kit (catalog A5003; Promega). qPCR was done using PowerUp SYBR Green Master Mix (catalog A25742; Applied Biosystems). Primer information is included in Supplemental Table 1.

Trypsin activity assay. Trypsin activity was assessed using the trypsin activity colorimetric assay kit (catalog ab102531; Abcam) according to the manufacturer's instructions. Briefly, small pieces of tissue (40-50 mg) were homogenized in $1 \mathrm{~mL}$ trypsin assay buffer and centrifuged at $13,000 \mathrm{~g}$ for 10 minutes at $4^{\circ} \mathrm{C}$. The total protein concentration of the supernatant was measured by BCA analysis, which was then used for the trypsin activity test.

Serum amylase activity. Serum amylase activity was measured in an aliquot of $10 \mu \mathrm{L}$ serum from each mouse using the Phadebas amylase test (Pharmacia Diagnostics) according to the manufacturer's instructions. Mixed arteriovenous blood was centrifuged at $1500 \mathrm{~g}$ for 10 minutes at $4^{\circ} \mathrm{C}$. After centrifugation, the plasma was used for measurement of amylase.

Western blot. Total pancreatic lysates were prepared by homogenizing the pancreata in SDS-containing sample buffer. Lysates were subjected to SDS-PAGE and transferred onto a PVDF membrane. The blots were incubated with primary antibodies and processed using standard protocols. The anti-PRSS1 rabbit polyclonal antibody (cata$\log$ AP10735c; 1:1000) was purchased from Abgent. The anti-GAPDH rabbit polyclonal antibody (catalog G8795; 1:5000) was obtained from MilliporeSigma. The anti-BAX rabbit polyclonal (catalog 2772s; 1:1000), anti-phospho-Histone H2A.X (Ser139) (clone 20E3) rabbit monoclonal (catalog 9718s: 1:1000), anti-phospho-Chk1 (Ser345) (clone 133D3) rabbit monoclonal (catalog 2348s; 1:1000), CHOP (clone L63F7) mouse monoclonal (catalog 2895; 1:1000), and Bip (clone C50B12) rabbit monoclonal (catalog 3177; 1:1000) antibodies were purchased from Cell Signaling. The anti-thrombin rabbit polyclonal (catalog ab83981; 1:500) and anti-p53 rabbit polyclonal (catalog ab31333; 1:500) antibodies were purchased from Abcam.

Histologic analysis. Pancreas tissue was fixed in 10\% neutral buffered formalin, embedded in paraffin, sectioned into $4-\mu \mathrm{m}$ thick sections, and stained with H\&E. Histology scores were evaluated in a blind manner (Supplemental Table 2).

Immunohistochemistry. Formalin-fixed, paraffin-embedded pancreas tissue was sectioned at $4-\mu \mathrm{m}$ thickness. Immunohistochemical staining was performed on the Dako Autostainer System (Agilent) according to the manufacturer's instructions. The anti-CD11b (clone EPR1344) rabbit monoclonal (catalog ab133357; 1:2000), anti-p53 rabbit polyclonal (catalog ab31333; 1:400), anti-p65 rabbit polyclonal (catalog ab16502; 1:400), anti-fibrinogen rabbit polyclonal (cata$\log$ ab34269; 1:1000) antibodies were purchased from Abcam. The anti-F4/80 (clone BM8) rat monoclonal (catalog sc-52664; 1:250), 8-OHdG rabbit polyclonal (catalog sc-139586; 1:80) antibodies were obtained from Santa Cruz. The anti-Gr-1 (clone RB6-8C5) rat monoclonal (catalog 14-5931-82;1:100) antibody was purchased from Thermo Fisher Scientific. The anticleaved caspase 3 rabbit polyclonal (catalog 9661s; 1:500) antibody was obtained from Cell Signaling.

TUNEL assay. Formalin-fixed, paraffin-embedded pancreas tissue sections (4- $\mu \mathrm{m}$ thick) were deparaffinized and rehydrated. After permeabilization with proteinase $\mathrm{K}$ solution, the tissue was refixed with formalin and equilibrated with the equilibration buffer. Then, sections were incubated for TUNEL staining using the DeadEnd Fluorometric TUNEL System (catalog G3250; Promega). Next, sections were mounted and counterstained with VECTASHIELD + DAPI (catalog H-1200; Vector Laboratories) for 15 minutes at room temperature. Sections incubated with rTdT incubation buffer (without rTdT enzyme) were used as the negative controls and sections treated with DNase I were used as the positive controls.

Morphologic analysis. All measurements were performed using Image-Pro Plus version 7.0.1 software (Media Cybernetics). Histologic evaluation of pancreas tissue was assessed on consecutive microscopic fields. Data were averaged and the results were expressed as the number of intranuclear positive areas per field.

Statistical analysis. All data were expressed as mean \pm SEM. Calculations were performed using GraphPad Prism 6.0. Two-tailed unpaired Student's $t$ test was used for comparisons between 2 groups. One-way or 2-way ANOVA was used for multiple group comparisons, and significant differences among the groups were assessed using Tukey's multiple comparisons test. Statistical significance levels are indicated as: ${ }^{*} P<0.05 ;{ }^{* *} P<0.01 ;{ }^{* *} P<0.001$.

Study approval. All animal experiments were approved by the IACUC at Mayo Clinic.

\section{Author contributions}

FG, YZ, and JW coordinated the project and were involved in most experiments including data collection and statistical analysis. The order of the co-first authors was assigned based on the relative con- 
tributions of these individuals. BJ, FG, and ANH drafted the manuscript. FG, YZ, YL, JG, and YW performed in vitro assays. FG, YZ, JW, X Zhan, JS, YY, JC, L Zhuang, CH, and X Zhu performed in vivo assays. BHE embedded and processed the tissues, H\&E, and IHC staining. L Zhang performed pathologic analysis. DM, ESR, L Zhang, $\mathrm{AL}$, and SJP participated in intellectual discussion during the project. $\mathrm{BJ}$ generated and characterized the transgenic mice. YB and BJ discovered the new use of dabigatran in pancreatitis therapy, supervised the study, finalized the manuscript, and secured funding support.

\section{Acknowledgments}

This work was supported by Department of Defense grants W81XWH-15-1-0257, R01 DK117910, K12 CA090628-18, and P50 CA102701. We greatly appreciate Miklos Sahin-Toth (Boston University) and Ilya Gukovsky (UCLA) for their critical comments.

Address correspondence to: Baoan Ji, Department of Cancer Biology, Mayo Clinic, 4500 San Pablo Road South, Jacksonville, Florida 32224, USA. Phone: 904.953.1789; Email:ji.baoan@mayo.edu.
1. Shaheen NJ, et al. The burden of gastrointestinal and liver diseases, 2006. Am J Gastroenterol. 2006;101(9):2128-2138.

2. Pandol SJ, Saluja AK, Imrie CW, Banks PA. Acute pancreatitis: bench to the bedside. Gastroenterology. 2007;132(3):1127-1151.

3. Sandler RS, et al. The burden of selected digestive diseases in the United States. Gastroenterology. 2002;122(5):1500-1511.

4. Yadav D, Lowenfels AB. The epidemiology of pancreatitis and pancreatic cancer. Gastroenterology. 2013;144(6):1252-1261.

5. Peery AF, et al. Burden of gastrointestinal disease in the United States: 2012 update. Gastroenterology. 2012;143(5):1179-1187.e3.

6. Lankisch PG, Apte M, Banks PA. Acute pancreatitis. Lancet. 2015;386(9988):85-96.

7. Lowenfels AB, Maisonneuve P, Whitcomb DC, Lerch MM, DiMagno EP. Cigarette smoking as a risk factor for pancreatic cancer in patients with hereditary pancreatitis. JAMA. 2001;286(2):169-170.

8. Weiss FU. Pancreatic cancer risk in hereditary pancreatitis. Front Physiol. 2014;5:70.

9. Kambhampati S, Park W, Habtezion A. Pharmacologic therapy for acute pancreatitis. World J Gastroenterol. 2014;20(45):16868-16880.

10. Chiari H. Über die Selbstverdauung des menschlichen Pankreas. Zeitschrift für Heilkunde. 1896;17:69-96.

11. Gilliland L, Steer ML. Effects of ethionine on digestive enzyme synthesis and discharge by mouse pancreas. Am J Physiol. 1980;239(5):G418-G426.

12. Koike H, Steer ML, Meldolesi J. Pancreatic effects of ethionine: blockade of exocytosis and appearance of crinophagy and autophagy precede cellular necrosis. Am JPhysiol. 1982;242(4):G297-G307.

13. Bialek R, Willemer S, Arnold R, Adler G. Evidence of intracellular activation of serine proteases in acute cerulein-induced pancreatitis in rats. Scand J Gastroenterol. 1991;26(2):190-196.

14. Willemer S, Bialek R, Adler G. Localization of lysosomal and digestive enzymes in cytoplasmic vacuoles in caerulein-pancreatitis. Histochemistry. 1990;94(2):161-170.

15. Leach SD, Modlin IM, Scheele GA, Gorelick FS. Intracellular activation of digestive zymogens in rat pancreatic acini. Stimulation by high doses of cholecystokinin. JClin Invest. 1991;87(1):362-366.

16. Blackstone M. Premature trypsin activation in hereditary pancreatitis. Gastroenterology. 1998;115(3):796-799.

17. Sahin-Tóth M, Tóth M. Gain-of-function mutations associated with hereditary pancreatitis enhance autoactivation of human cationic trypsinogen. Biochem Biophys Res Commun. 2000;278(2):286-289.

18. Weber P, Keim V, Zimmer KP. Hereditary pancreatitis and mutation of the trypsinogen gene. Arch Dis Child. 1999;80(5):473-474.

19. Whitcomb DC. Hereditary pancreatitis: new insights into acute and chronic pancreatitis. Gut. 1999;45(3):317-322.

20. Whitcomb DC, et al. Hereditary pancreatitis is caused by a mutation in the cationic trypsinogen gene. Nat Genet. 1996;14(2):141-145.

21. Wyllie R. Hereditary pancreatitis. Am J Gastroenterol. 1997;92(7):1079-1080.

22. Le Bodic L, et al. The hereditary pancreatitis gene maps to long arm of chromosome 7. Hum Mol Genet. 1996;5(4):549-554.

23. Pandya A, et al. Linkage studies in a large kindred with hereditary pancreatitis confirms mapping of the gene to a $16-\mathrm{cM}$ region on 7q. Genomics. 1996;38(2):227-230.

24. Athwal T, et al. Expression of human cationic trypsinogen (PRSS1) in murine acinar cells promotes pancreatitis and apoptotic cell death. Cell Death Dis. 2014;5:e1165.

25. Hegyi E, Sahin-Tóth M. Genetic risk in chronic pancreatitis: the trypsin-dependent pathway. Dig Dis Sci. 2017;62(7):1692-1701.

26. Németh BC, Sahin-Tóth M. Human cationic trypsinogen (PRSS1) variants and chronic pancreatitis. Am J Physiol Gastrointest Liver Physiol. 2014;306(6):G466-G473.

27. Németh BC, Wartmann T, Halangk W, Sahin-Tóth M. Autoactivation of mouse trypsinogens is regulated by chymotrypsin $\mathrm{C}$ via cleavage of the autolysis loop. J Biol Chem. 2013;288(33):24049-24062.

28. Szabó A, Sahin-Tóth M. Increased activation of hereditary pancreatitis-associated human cationic trypsinogen mutants in presence of chymotrypsin C. J Biol Chem. 2012;287(24):20701-20710.

29. Warming S, Costantino N, Court DL, Jenkins NA Copeland NG. Simple and highly efficient BAC recombineering using galK selection. Nucleic Acids Res. 2005;33(4):e36.

30. Whitcomb DC. Genetic risk factors for pancreatic disorders. Gastroenterology. 2013;144(6):1292-1302.

31. Saluja AK, Lerch MM, Phillips PA, Dudeja V. Why does pancreatic overstimulation cause pancreatitis? Annu Rev Physiol. 2007;69:249-269.

32. Sahin-Tóth M, Gráf L, Tóth M. Trypsinogen stabilization by mutation Arg117-->His: a unifying pathomechanism for hereditary pancreatitis? Biochem Biophys Res Commun. 1999;264(2):505-508.
33. Zhan X, Wang F, Bi Y, Ji B. Animal models of gastrointestinal and liver diseases. Animal models of acute and chronic pancreatitis. Am J Physiol Gastrointest Liver Physiol. 2016;311(3):G343-G355.

34. Huang $\mathrm{H}$, et al. Activation of nuclear factor- $\kappa \mathrm{B}$ in acinar cells increases the severity of pancreatitis in mice. Gastroenterology. 2013;144(1):202-210.

35. Fridman JS, Lowe SW. Control of apoptosis by p53. Oncogene. 2003;22(56):9030-9040.

36. Yin C, Knudson CM, Korsmeyer SJ, Van Dyke T. Bax suppresses tumorigenesis and stimulates apoptosis in vivo. Nature.1997;385(6617):637-640.

37. Reinhardt HC, Schumacher B. The p53 network: cellular and systemic DNA damage responses in aging and cancer. Trends Genet. 2012;28(3):128-136.

38. Gaiser S, et al. Intracellular activation of trypsinogen in transgenic mice induces acute but not chronic pancreatitis. Gut. 2011;60(10):1379-1388.

39. Ji B, Gaiser S, Chen X, Ernst SA, Logsdon CD. Intracellular trypsin induces pancreatic acinar cell death but not NF-kappaB activation. J Biol Chem. 2009;284(26):17488-17498.

40. Chakravarthi S, Jessop CE, Bulleid NJ. The role of glutathione in disulphide bond formation and endoplasmic-reticulum-generated oxidative stress. EMBO Rep. 2006;7(3):271-275.

41. Pollard MG, Travers KJ, Weissman JS. Ero1p: a novel and ubiquitous protein with an essential role in oxidative protein folding in the endoplasmic reticulum. Mol Cell. 1998;1(2):171-182.

42. Singhi AD, et al. The histopathology of PRSS1 hereditary pancreatitis. Am J Surg Pathol. 2014;38(3):346-353.

43. Németh BC, Sahin-Tóth M. Human cationic trypsinogen (PRSS1) variants and chronic pancreatitis. Am J Physiol Gastrointest Liver Physiol. 2014;306(6):G466-G473.

44. Corey DR, Craik CS. An investigation into the minimum requirements for peptide hydrolysis by mutation of the catalytic triad of trypsin. JAm Chem Soc. 1992;114:1784-1790.

45. Geisz A, Sahin-Tóth M. A preclinical model of chronic pancreatitis driven by trypsinogen autoactivation. Nat Commun. 2018;9(1):5033.

46. Foley JH, Conway EM. Cross talk pathways between coagulation and inflammation. Circ Res. 2016;118(9):1392-1408.

47. Esmon CT. The interactions between inflammation and coagulation. Br J Haematol. 2005;131(4):417-430.

48. Camerer E, Huang W, Coughlin SR. Tissue factorand factor $\mathrm{X}$-dependent activation of proteaseactivated receptor 2 by factor VIIa. Proc Natl Acad Sci USA. 2000;97(10):5255-5260. 
49. Demetz G, et al. Tissue factor-factor VIIa complex induces cytokine expression in coronary artery smooth muscle cells. Atherosclerosis. 2010;212(2):466-471.

50. Esmon CT. Targeting factor Xa and thrombin: impact on coagulation and beyond. Thromb Haemost. 2014;111(4):625-633.

51. Michael ES, Kuliopulos A, Covic L, Steer ML, Perides G. Pharmacological inhibition of PAR2 with the pepducin P2pal-18S protects mice against acute experimental biliary pancreatitis. Am J Physiol Gastrointest Liver Physiol. 2013;304(5):G516-G526.

52. Posma JJ, Posthuma JJ, Spronk HM. Coagulation and non-coagulation effects of thrombin. J Thromb Haemost. 2016;14(10):1908-1916.

53. Kakafika A, Papadopoulos V, Mimidis K, Mikhailidis DP. Coagulation, platelets, and acute pancreatitis. Pancreas. 2007;34(1):15-20.

54. Kyhälä L, et al. Activated protein C retards recovery from coagulopathy in severe acute pancreatitis. Scand J Clin Lab Invest. 2016;76(1):10-16.
55. Li S, Cao G, Chen X, Wu T. Low-dose heparin in the prevention of post endoscopic retrograde cholangiopancreatography pancreatitis: a systematic review and meta-analysis. Eur J Gastroenterol Hepatol. 2012;24(5):477-481.

56. Ji B, et al. Robust acinar cell transgene expression of CreErT via BAC recombineering. Genesis. 2008;46(8):390-395.

57. Selig L, et al. Characterisation of a transgenic mouse expressing R122H human cationic trypsinogen. BMC Gastroenterol. 2006;6:30.

58. Niederau C, Liddle RA, Ferrell LD, Grendell JH. Beneficial effects of cholecystokinin-receptor blockade and inhibition of proteolytic enzyme activity in experimental acute hemorrhagic pancreatitis in mice. Evidence for cholecystokinin as a major factor in the development of acute pancreatitis. JClin Invest. 1986;78(4):1056-1063.

59. Lankisch PG, et al. Effect of FOY-305 (camostate) on severe acute pancreatitis in two experimental animal models. Gastroenterology. 1989;96(1):193-199.
60. Satoh H, Harada M, Tashiro S, Shiroya T, Imawaka H, Machii K. The effect of continuous arterial infusion of gabexate mesilate (FOY-007) on experimental acute pancreatitis. J Med Invest. 2004;51(3-4):186-193.

61. Seta T, Noguchi Y, Shimada T, Shikata S, Fukui T. Treatment of acute pancreatitis with protease inhibitors: a meta-analysis. Eur J Gastroenterol Hepatol. 2004;16(12):1287-1293.

62. Singh VP, Chari ST. Protease inhibitors in acute pancreatitis: lessons from the bench and failed clinical trials. Gastroenterology. 2005;128(7):2172-2174.

63. De Caterina R, D'Ugo E, Libby P. Inflammation and thrombosis - testing the hypothesis with anti-inflammatory drug trials. Thromb Haemost. 2016;116(6):1012-1021.

64. Dawra R, Sharif R, Phillips P, Dudeja V, Dhaulakhandi D, Saluja AK. Development of a new mouse model of acute pancreatitis induced by administration of L-arginine. Am J Physiol Gastrointest Liver Physiol. 2007;292(4):G1009-G1018. 